\title{
Myoblast replication is reduced in the IUGR fetus despite maintained proliferative capacity in vitro
}

\author{
Susan M Soto1,*, Amy C Blake1,*, Stephanie R Wesolowski', Paul J Rozance1, \\ Kristen B Barthel2 ${ }^{2}$, Bifeng Gao ${ }^{3}$, Byron Hetrick ${ }^{4}$, Carrie E McCurdy4, \\ Natalia G Garza', William W Hay Jr', Leslie A Leinwand², Jacob E Friedman' and \\ Laura D Brown' \\ 1Department of Pediatrics, University of Colorado School of Medicine, Perinatal Research Center, \\ Aurora, Colorado, USA \\ 2Department of Molecular, Cellular, and Developmental Biology, University of Colorado Boulder, \\ BioFrontiers Institute, Boulder, Colorado, USA \\ 3Department of Medicine, University of Colorado School of Medicine, Aurora, Colorado, USA \\ ${ }^{4}$ Department of Human Physiology, University of Oregon, Eugene, Oregon, USA \\ *(S M Soto and A C Blake contributed equally to this work)
}

Correspondence should be addressed to L D Brown Email

Laura.Brown@ucdenver.edu

\begin{abstract}
Adults who were affected by intrauterine growth restriction (IUGR) suffer from reductions in muscle mass and insulin resistance, suggesting muscle growth may be restricted by molecular events that occur during fetal development. To explore the basis of restricted fetal muscle growth, we used a sheep model of progressive placental insufficiency-induced IUGR to assess myoblast proliferation within intact skeletal muscle in vivo and isolated myoblasts stimulated with insulin in vitro. Gastrocnemius and soleus muscle weights were reduced by $25 \%$ in IUGR fetuses compared to those in controls (CON). The ratio of PAX7+ nuclei (a marker of myoblasts) to total nuclei was maintained in IUGR muscle compared to CON, but the fraction of PAX7+ myoblasts that also expressed Ki-67 (a marker of cellular proliferation) was reduced by $23 \%$. Despite reduced proliferation in vivo, fetal myoblasts isolated from IUGR biceps femoris and cultured in enriched media in vitro responded robustly to insulin in a dose- and time-dependent manner to increase proliferation. Similarly, insulin stimulation of IUGR myoblasts upregulated key cell cycle genes and DNA replication. There were no differences in the expression of myogenic regulatory transcription factors that drive commitment to muscle differentiation between CON and IUGR groups. These results demonstrate that the molecular machinery necessary for transcriptional control of proliferation remains intact in IUGR fetal myoblasts, indicating that in vivo factors such as reduced insulin and IGF1, hypoxia and/or elevated counter-regulatory hormones may be inhibiting muscle growth in IUGR fetuses.
\end{abstract}

\author{
Key Words \\ - skeletal muscle \\ - myogenesis \\ - muscle growth \\ - fetal programming
}

Journal of Endocrinology

(2017) 232, 475-491
๑ 2017 Society for Endocrinology Printed in Great Britain
Published by Bioscientifica Ltd 


\section{Introduction}

In pregnancies affected by intrauterine growth restriction (IUGR), a poorly functioning placenta restricts nutrient supply to the fetus, preventing normal fetal growth (Marconi \& Paolini 2008, Figueras \& Gardosi 2011). Fetal skeletal muscle growth is vulnerable under conditions of placental insufficiency because blood flow and nutrients are preferentially shunted to vital organs, such as the brain, heart and adrenal glands, in response to decreasing fetal oxygenation (Tchirikov et al. 1998, Yajnik 2004). As a result, skeletal muscle growth is restricted. In IUGR fetuses and neonates, body composition analyses show $25-40 \%$ reductions in muscle mass when compared to appropriatefor-gestational age counterparts (Yau \& Chang 1993, Padoan et al. 2004, Larciprete et al. 2005). Adults who were affected by IUGR suffer from lifelong reductions in muscle mass (Sayer et al. 2008) and lower muscle/fat ratios when compared to a higher birth weight group (Kensara et al. 2005, Yliharsila et al. 2007), suggesting that postnatal muscle growth may be restricted by molecular events that occur during fetal development. Reduced fetal skeletal muscle growth and insulin resistance may contribute to long-term morbidities that occur as a result of IUGR, such as coronary heart disease and type 2 diabetes (Gluckman et al. 2008, Kanaka-Gantenbein 2010).

The fetal period is a critical time for the establishment of skeletal muscle mass. Myogenesis occurs by fetal myoblast proliferation followed by the expression of myogenic regulatory factors (MRFs) that promote differentiation and fusion of fetal myoblasts into multinucleated myotubes (Gerrard \& Grant 2003, Fahey et al. 2005b). Expression of paired box protein 7 (PAX7) denotes a myoblast that has not terminally differentiated and has the capacity to enter the cell cycle and proliferate (Relaix et al. 2005). MRFs are a set of transcription factors, including MYF5, MYOD, MYF6 and $M Y O G$, that are expressed in a sequential manner during the differentiation process (Berkes \& Tapscott 2005, Braun \& Gautel 2011). Myogenesis is nearly complete by the end of gestation, such that a full complement of myofibers is present at the time of birth, and postnatal muscle growth occurs primarily by hypertrophy (Rowe \& Goldspink 1969, Wigmore \& Stickland 1983, Fahey et al. 2005b).

Myogenesis is regulated in part by the fetal growth factors, particularly insulin and insulin-like growth factors (IGFs). Insulin and insulin-like growth factor-1 (IGF1) are reduced in the circulating plasma of IUGR fetal sheep (Brown 2014). In addition to growth factor deficiencies, models of IUGR demonstrate further pathophysiological abnormalities, such as fetal hypoxemia and increased cortisol and norepinephrine concentrations (Pardi et al. 1993, Regnault et al. 2007, Leos et al. 2010), which can adversely influence muscle growth (Milley 1995, 1997, Jellyman et al. 2012). Thus, it is possible that the hormonal milieu in the IUGR fetus may adversely affect myoblast proliferation and differentiation, with the potential for long-lasting effects on muscle mass because of reduced myofiber number (Widdowson et al. 1972).

We hypothesized that IUGR fetal sheep myoblasts would have reduced proliferation rates as a result of the endocrine milieu, and thus, the intrinsic capacity of IUGR myoblasts to respond to growth stimuli in vitro would remain intact. To test these hypotheses, we used a wellestablished sheep model of IUGR produced by placental insufficiency (Thureen et al. 1992, Limesand et al. 2007, Regnault et al. 2007, 2013). These sheep develop progressive placental insufficiency as a result of exposure to elevated ambient temperatures during mid-gestation (Bell et al. 1987). This model shares many phenotypic characteristics with human placental insufficiency including lower rates of amino acid, glucose and oxygen transfer to the fetus (Barry et al. 2008) and leads to a fetal phenotype that is strikingly similar to that of other sheep models of placental dysfunction produced by very different mechanisms (Morrison 2008). We examined cell-specific proliferation capacity in vivo and in myoblasts in vitro, along with the capacity of insulin to stimulate genes that control myoblast proliferation and differentiation.

\section{Materials and methods}

\section{Animal treatments}

Columbia-Rambouillet mixed-breed sheep with singleton pregnancies were studied at the University of Colorado Perinatal Research Center using protocols approved by the Institutional Animal Care and Use Committee. The Perinatal Research Center is accredited by the American Association for the Accreditation of Laboratory Animal Care. Pregnant sheep were housed in an environmental chamber with elevated ambient temperatures $\left(40^{\circ} \mathrm{C}\right.$ for $12 \mathrm{~h} ; 35^{\circ} \mathrm{C}$ for $12 \mathrm{~h}$ ) and $40 \%$ humidity from $\sim 40$-day gestation (dga, term $=147 \mathrm{dga}$ ) to $\sim 115$ dga to produce placental insufficiency and asymmetric intrauterine growth restriction (IUGR group; $n=21$ ) (Bell et al. 1987, Brown et al. 2012). Control ewes were housed in the same facility at ambient temperatures and normal humidity (CON group;

Published by Bioscientifica Ltd 
$n=20$ ). Sheep were kept in individual pens alongside other sheep. After treatment, all sheep were housed in ambient temperatures and humidity for the remainder of the studies. All sheep were given ad libitum access to water. Maternal feed intake was matched on an absolute basis between sheep in CON and IUGR groups, and maternal weight-adjusted feed intake did not differ between groups.

Late-gestation pregnant sheep underwent a surgical procedure for fetal and maternal catheter placement according to methods previously published (Brown et al. 2012). Briefly, sheep were fasted for $24 \mathrm{~h}$ and thirsted for $12 \mathrm{~h}$ prior to surgery. A maternal jugular catheter was placed for administration of diazepam $(0.2 \mathrm{mg} / \mathrm{kg})$ and ketamine $(20 \mathrm{mg} / \mathrm{kg})$, and ewes were then maintained on isoflurane inhalation anesthesia (2-4\%) for the remainder of the surgical procedure. Maternal laparotomy and hysterotomy were performed, and the fetal abdominal aorta and fetal femoral veins were catheterized. Postsurgical recovery was a minimum of 5 days. Some animals included in this study served as saline-infused fetuses in a previously published study (Brown et al. 2012). On the day prior to tissue collection, fetal arterial blood was obtained for measurements of $\mathrm{pH}, \mathrm{PaCO}_{2}, \mathrm{PaO}_{2}$, $\mathrm{O}_{2}$ saturation, $\mathrm{O}_{2}$ content and hematocrit, and plasma for measuring concentrations of insulin, IGF1, glucose, lactate, cortisol and norepinephrine using biochemical methods previously described (Limesand et al. 2006, Brown et al. 2012).

\section{Fetal skeletal muscle collection}

Ewes received diazepam $(0.2 \mathrm{mg} / \mathrm{kg})$ and ketamine $(20 \mathrm{mg} / \mathrm{kg})$ intravenously, and fetuses were delivered via maternal laparotomy and hysterotomy. The biceps femoris muscle was exposed, and a biopsy was obtained from the anesthetized fetus. A portion of the muscle was immediately frozen in liquid nitrogen and stored at $-70^{\circ} \mathrm{C}$, and the remaining muscle was placed in Ham's F12 media for myoblast isolation. Intravenous pentobarbital sodium (Fatal Plus; Vortech Parmaceuticals, Dearborn, MI, USA) was administered to both the mother and the fetus, after which the fetus was weighed and crown-rump and lower extremity limb lengths were determined. Fetal lower extremity limb length was measured from the femoral head to the top edge of the hoof. In a subset of fetuses, muscles of the fetal hindlimb were collected to include a variety of oxidative and glycolytic muscles (biceps femoris, soleus, tibialis anterior and gastrocnemius) (Suzuki \& Tamate 1988, Finkelstein et al. 1992,
Konno \& Suzuki 2000) and were weighed within $15 \mathrm{~min}$ post-mortem. Muscle mid-bellies from the biceps femoris, tibialis anterior and soleus muscles were placed on corkboard thinly coated with optimal cutting temperature media, frozen in liquid nitrogen-cooled isopentane for $60 \mathrm{~s}$ and stored at $-70^{\circ} \mathrm{C}$.

\section{Gene expression arrays, RNA extraction and quantitative real-time PCR analysis}

Total RNA was isolated from biceps femoris muscle using TRIzol LS (Invitrogen) and further purified using RNeasy Mini Kit (Qiagen) according to the manufacturer's instructions and as previously described (Brown et al. 2014). Gene expression data were collected at the Genomics and Microarray Core of the University of Colorado using Affymetrix GeneChip Bovine Genome Arrays (Affymetrix). Total RNA (300ng) was primed with T7 oligo primer to synthesize cDNA and introduce a T7 promoter. Single-stranded cDNA was converted to doublestranded DNA template for transcription. The cDNA was used directly in the In Vitro Transcription (IVT) reaction to synthesize Biotin-Modified cRNA. $10 \mu \mathrm{g}$ of cRNA was hybridized on the Affymetrix Bovine GeneChip with rotation at $0.3 \mathrm{~g}$ for $16 \mathrm{~h}$ at $45^{\circ} \mathrm{C}$. Chips were washed and scanned using a GeneChip Fluidics Station 450 and scanned using a GeneChip Scanner 3000 (Affymetrix). Skeletal muscle from each individual animal was run separately. Scanned chip images were analyzed and normalized using a multiarray averaging method. Genes that differed between treatment groups were identified using a statistical limit of $P \leq 0.05$ and fold enrichment $\leq / \geq 1.5$ using Affymetrix Expression Console Software. Functional annotation of differentially expressed genes, including the assignment of genes to gene ontology functional categories and Kyoto Encyclopedia of Genes and Genomes (KEGG) pathway processes, was performed using Database for Annotation, Visualization, and Integrated Discovery (DAVID) (Dennis et al. 2003). Gene expression data have been deposited in the National Center for Biotechnology Information Gene Expression Omnibus (GEO) (Edgar et al. 2002) and are accessible through GEO Series accession number GSE64578 (http://www.ncbi. nlm.nih.gov/geo/query/acc.cgi?acc=GSE64578).

To validate differentially expressed genes identified by KEGG pathway analysis, RNA was extracted from muscle tissue, reverse transcribed and used in quantitative real-time PCR using the $\Delta \Delta C_{\mathrm{T}}$ method (LightCycler 480 II; Roche Life Science) as previously described

Published by Bioscientifica Ltd. 
Table 1 Primers used for real-time PCR assays.

\begin{tabular}{|c|c|}
\hline Gene & Gene product \\
\hline CCNE2 & Cyclin E2 \\
\hline$C D K N 2 C$ & p18 \\
\hline MCM6 & $\begin{array}{l}\text { Minichromosome maintenance } \\
\text { complex component } 6\end{array}$ \\
\hline PLK1 & Polo like kinase 1 \\
\hline CCNB1 & Cyclin B1 \\
\hline CCNB2 & Cyclin B2 \\
\hline$C D K 1$ & Cyclin-dependent kinase 1 \\
\hline$C D C 20$ & Cyclin-dependent kinase 20 \\
\hline MAD2 & Spindle checkpoint protein MAD2 \\
\hline$B \cup B 1 B$ & $\begin{array}{l}\text { BUB1 mitotic checkpoint serine/ } \\
\text { threonine kinase } B\end{array}$ \\
\hline ESPL1 & Extra spindle pole bodies like 1 \\
\hline CHEK1 & Checkpoint kinase 1 \\
\hline PAX7 & Paired box 7 \\
\hline MYF5 & Myogenic factor 5 \\
\hline MYF6 & Myogenic factor 6 (MRF4) \\
\hline MYOD & Myogenic differentiation 1 \\
\hline MYOG & Myogenin \\
\hline DES & Desmin \\
\hline$A C T B$ & Actin beta \\
\hline GAPDH & $\begin{array}{l}\text { Glyceraldehyde-3-phosphate } \\
\text { dehydrogenase }\end{array}$ \\
\hline RPS15 & Ribosomal protein S15 \\
\hline
\end{tabular}

Forward
TGATGGTGCTTGCAGTGAAGAGGA
TTGGAAGGACTGCGCTGCA
TGATTCCCGAGTCAGTGGTGTTGA
GAGCTGCTCAATGACGAGTT
TGGGTCGTGAAGTCACTGGAAACA
AACCCACATTTCCTGGATGGGAGA
ACACATGAGGTAGTGACACTCTGG
TGTAGAGGAAGCCAAGATCC
CGAGTGCAGAAATATGGACTCACC
CATAAGAAGCTGCACCAGGT

AGCAGCTGTACTGACAAGCGAGAA TGCCTGAACAAGATGCTCAGAGGT AGCTACCGGACTCCACCTA AAGGTGGAGATCCTCAGGAA TTCAGCTACAGACCCAAGCAGGAA GCAATCCGCTATATCGAAGG GCGCACTGGAGTTTGGCC GGACCTGCTCAATGTCAAGAT TGCAGAAAGAGATCACTGCC TGGAGGGACTTATGACCACTG

\section{Reverse \\ GACCGTTACAGGACAAAGTTCCCA CGCATCATGAATGACAGCGA CAAACCTTGGGTTGGTTGGT \\ CACGGGGTTCTCCATGCC CAGCATCTTCTTGGGCACACAGTT ATATCGGTCCATGACGGCAACACA ATGTCCACTGGAGTTGAGTAGCGA GGCCTTCTGGCTATAGAGTA TGCCATCTTTCAAGGACCTCTCCA CGGAGCTCTTAGTTCCTGC}

TTCCAGCCACATTGCTGTAGTGAC
TTATGCCGAAACACGGTTGCCAAG
CCCTGGTGCATGGTGGAC
ATTCAGGCATGCCATCAGAGCAAC
TTGTCCCTCCTTCCTTGGCAGTTA
GTAGTAAGCGCGGTCGTAGC
ACTGTGATGCTGTCCACGAT
AAGGTCTGGATAGGGAGGTT
GACAGCGAGGCAGGATGG
TAGAAGCAGGGATGATGTTCT

ATCATTCTGCCCGAGATGGTG

CGGGCCGGCCATGCTTTACG
(Thorn et al. 2009, Brown et al. 2014). Primers developed for all real-time PCR assays are shown in Table 1. Gene expression was normalized to the average of three normalizers: ACTB, GAPDH and RPS15.

\section{Immunohistochemistry}

Isopentane-preserved biceps femoris, tibialis anterior and soleus muscles were removed from corkboard, and $14 \mu \mathrm{m}$ sections were prepared as previously described (Brown et al. 2016). Muscle sections were incubated with the following antibodies: anti-PAX7 mouse monoclonal IgG (1:100; Developed by Tokyo Institute of Technology and obtained from the Developmental Studies Hybridoma Bank, created by the NICHD of the NIH and maintained at The University of Iowa, Department of Biology, Iowa City, IA, USA), anti-Ki-67 rabbit monoclonal IgG (1:250; Cell Signaling Technology), anti-laminin rabbit polyclonal IgG (1:100, Sigma-Aldrich), anti-myosin heavy chain (MHC) Type I (slow) mouse monoclonal IgG (1:20; Vector Laboratories, Burlingame, CA, USA) and anti-MHC Type IIa mouse IgG (1:2; a gift from Dr Leslie Leinwand, Boulder, CO). Immunocomplexes were detected with polyclonal IgG goat anti-mouse conjugated to Alexa Fluor 594 (1:100; Thermo Fisher), goat anti-rabbit conjugated to Alexa Fluor 488 (1:100; Thermo Fisher) and donkey anti-rabbit conjugated to AMCA (1:250; Jackson
ImmunoResearch Laboratories) and counterstained with DAPI (1:1000; Sigma-Aldrich). Fluorescent images were visualized and quantified using the Count and Measure module within CellSens Dimension Imaging Software (Olympus America Inc.). PAX7+ nuclei were expressed as a ratio to total nuclei identified with DAPI and also quantified per myofiber. Nuclei that expressed both Ki-67 and PAX7 (signifying a PAX7+ cell that is replicating) are shown as a ratio of PAX7+ and $\mathrm{Ki}-67+$ nuclei to total PAX7+ nuclei. Cross-sectional area of type I and IIa MHC myofibers was quantified using CellSens Imaging Software. For each muscle, a minimum of 2500 total nuclei and 250 myofibers per fetus were analyzed from a minimum of 4 representative sections.

\section{Primary myoblast cultures}

Myoblasts were harvested and cultured from fresh biopsies of biceps femoris muscle using a modification of previously published protocols (Harper et al. 1987). Connective tissue was removed while the muscle was incubating in Ham's F12 media. Muscle was digested in trypsin $(0.05 \%$ in $0.53 \mathrm{mM}$ EDTA in Hank's balanced salt solution buffer; Mediatech, Manassas, VA, USA) for $30 \mathrm{~min}$ after which the supernatant was removed and kept on ice, and the step was repeated with fresh trypsin. Fetal bovine serum (5\% FBS; HyClone; GE Healthcare Life Sciences)

Published by Bioscientifica Ltd. 
was added to the pooled supernatant, and myoblasts were centrifuged at $530 \mathrm{~g}$ for $6 \mathrm{~min}$. Myoblasts were re-suspended in Clonetics Skeletal Muscle Growth Media with BulletKit (SkGM; Lonza, Walkersville, MO, USA) and L-glutamine (Sigma-Aldrich). BulletKit components added to the media included dexamethasone, bovine serum albumin (BSA), bovine fetuin, human recombinant epidermal growth factor, gentamicin and amphotericin-B. A pre-plating step was performed to remove fibroblasts by incubating myoblasts for $45 \mathrm{~min}$ at $37^{\circ} \mathrm{C}$. Supernatant was applied to flasks (Becton Dickinson, Franklin Lakes, NJ, USA) with rat-tail collagen coating (Corning) for $24 \mathrm{~h}$, at which point the media was changed to SkGM with additional 10\% FBS. Myoblasts were passaged and stored in $10 \%$ dimethyl sulfoxide (DMSO, Sigma-Aldrich) in SkGM. Myoblasts were thawed and passaged at least once prior to proliferation studies. All studies were performed on passages 3 through 6 .

To assess myoblast purity of the primary cultures, myoblasts from passages 3 through 6 were suspended in PBS and stained with Live/Dead Fixable Violet (Thermo Fisher) according to manufacturer's instructions. Myoblasts were fixed in 4\% PFA for $15 \mathrm{~min}$, permeabilized with $0.1 \%$ Triton-X 100 in PBS for $30 \mathrm{~min}$ and re-suspended in 50\% methanol in PBS and stored overnight at $4^{\circ} \mathrm{C}$. Myoblasts were washed in incubation buffer $(0.5 \%$ BSA in PBS) and then singly or in combination stained with $1 \mu \mathrm{g}$ anti-Desmin rabbit monoclonal IgG conjugated to Alexa Fluor 488 (Abcam), $1 \mu \mathrm{g}$ anti-PAX7 mouse monoclonal IgG (Abcam) conjugated to goat anti-mouse IgG Alexa Fluor 647 (1:1000; Abcam) and/or $5 \mu \mathrm{L}$ anti-CD56 mouse monoclonal IgG conjugated to Horizon BV605 (BD Biosciences, San Jose, CA, USA) in $100 \mu \mathrm{L}$ incubation buffer for $30 \mathrm{~min}$ at room temperature. Myoblasts were washed with incubation buffer, re-suspended in PBS and counted using a Gallios flow cytometer and Kaluza software (Beckman Coulter, Indianapolis, IN, USA). Gates were determined by comparing unstained and singly stained samples.

\section{Assessment of myoblast proliferative capacity in vitro}

Myoblast proliferation rates were measured in response to insulin. Two different basal media conditions (without supplemental insulin) were used: (1) nutrient-enriched skeletal muscle growth media (SkGM with 10\% FBS and $4 \mathrm{mM}$ glutamine) to maximize growth conditions and (2) minimally supportive media (HyClone DMEM with $1 \mathrm{~g} / \mathrm{L}$ glucose, $1 \%$ FBS, $0.1 \%$ BSA and $4 \mathrm{mM}$ glutamine) to further isolate the effects of insulin on myoblast growth.

Proliferation in nutrient-enriched skeletal muscle growth media Myoblasts were plated at $10^{5}$ per well in 6-well plates (TPP brand, Life Science Products, Frederick, CO, USA) and incubated in SkGM and 5\% FBS for $24 \mathrm{~h}$. Myoblasts were serum starved in DMEM with $1 \%$ BSA to synchronize the cell cycle for $16 \mathrm{~h}$, and baseline myoblasts counts were obtained. To determine the dose- and time-dependent proliferative response to insulin, myoblasts were incubated in SkGM with 1\% FBS with $0,1,10$ or $100 \mathrm{nM}$ insulin (Humulin R, Eli Lilly). On 3 and 5 days of incubation, myoblasts were trypsinized (0.25\%; Mediatech) and counted manually using a hemocytometer. In those myoblasts incubated for 5 days, media was changed on day 3.

\section{Proliferation in minimally supportive} media To further isolate the effect of insulin (100 nM) apart from multiple other growth factors contained in SkGM, myoblasts were plated at $10^{5}$ per well and incubated in minimally supportive media (DMEM, 1\% FBS, 0.1\% BSA and $1 \%$ glutamine) for $48 \mathrm{~h}$. Myoblasts were serum starved for $16 \mathrm{~h}$, baseline cell counts were obtained and then incubated in DMEM with 0 nM insulin, 100nM insulin or $100 \mathrm{nM}$ insulin with 1\% FBS. Myoblasts were counted using a hemocytometer after 3 and 5 days of treatment. In those myoblasts incubated for 5 days, media was changed on day 3. Myoblasts that were treated with DMEM $0 \mathrm{nM}$ insulin and DMEM $100 \mathrm{nM}$ insulin with 1\% FBS for 5 days also were harvested in buffer RLT (Qiagen) for RNA extraction.

DNA synthesis was measured by ${ }^{3} \mathrm{H}$-thymidine incorporation (Grill \& Cohick 2000). Myoblasts were plated at $10^{4}$ per well in 48 -well plates (CellTreat, Shirley, MA, USA) in SkGM with 1\% FBS for $24 \mathrm{~h}$. Myoblasts were serum starved for $16 \mathrm{~h}$ and incubated in DMEM with $0 \mathrm{nM}$ insulin, $100 \mathrm{nM}$ insulin or $100 \mathrm{nM}$ insulin with 1\% FBS for 3 and 5 days. Twenty-four hours prior to study, methyl-3H-thymidine $(0.5 \mu \mathrm{Ci}$; Cambridge Laboratories, Andover, MA, USA) was added to each well. Myoblasts were washed with PBS, incubated in ice-cold $5 \%$ trichloroacetic acid (Sigma-Aldrich) and solubilized in $0.1 \mathrm{M} \mathrm{NaOH} / 1 \%$ SDS for $1 \mathrm{~h}$ at room temperature. Lysate was transferred to scintillation vials containing $20 \mathrm{~mL}$ of scintillation fluid (Bio-Safe II; Research Products International Corporation, Mt. Prospect, IL, USA) and disintegrations per min of labeled thymidine were 
determined using a Packard TriCarb 2300TR Liquid Scintillation Analyzer (PerkinElmer).

Insulin signaling Signaling through AKT and mTOR was assessed in response to insulin in CON and IUGR myoblasts. Myoblasts were plated at $10^{5}$ per well in 6-well plates and incubated in SkGM and 5\% FBS for $24 \mathrm{~h}$ (or until cells were $70 \%$ confluent). Myoblasts were serum starved for $16 \mathrm{~h}$ in DMEM and exposed to insulin at 0,1 and $10 \mathrm{nM}$ concentrations for 10,30 and $60 \mathrm{~min}$. Myoblasts were washed with ice-cold PBS, and lysis buffer was added $(50 \mu \mathrm{L}$ per well; $20 \mathrm{mM}$ Tris- $\mathrm{HCl}, 150 \mathrm{mM} \mathrm{NaCl}$, $2 \mathrm{mM}$ EDTA, $2.5 \mathrm{mM}$ Na pyrophosphate, $20 \mathrm{mM} \mathrm{NaF}$ ) with $0.004 \% \mathrm{v} / \mathrm{v}$ phosphatase inhibitor II/III (Sigma-Aldrich) and $0.01 \% \mathrm{v} / \mathrm{v}$ protease inhibitor (Sigma-Aldrich). Lysate was centrifuged at $17,000 \boldsymbol{g}$ for $10 \mathrm{~min}$, and supernatant was stored at $-70^{\circ} \mathrm{C}$. Protein quantification, gel electrophoresis and transfer to nitrocellulose membranes was performed as previously reported (Brown et al. 2012). Membranes were incubated with the following primary rabbit polyclonal IgG antibodies: phospho-AKT (S473), total AKT, phospho-p44/42 (Thr202/Tyr204) extracellular signal-regulated kinase (ERK1/2), total p44/42 ERK1/2, phospho-P70S6K (Thr389), total P70S6K, phosphomTOR (S2448) and total mTOR (1:1000; Cell Signaling Technology). Actin mouse monoclonal IgG (1:100,000; MP Biomedicals, Santa Ana, CA, USA) was used as a loading control.

\section{Expression of muscle regulatory factors} Myoblasts were plated at $10^{5}$ per well in 6-well plates and incubated in SkGM and 10\% FBS until cells were 70-90\% confluent (day 0). Myoblasts were then incubated in DMEM with 1\% BSA and 2\% FBS to induce differentiation. Cells were harvested in buffer RLT on days $0,2,5$ and 8 of the differentiation process. Carrier RNA $(5 \mu \mathrm{L})$ was added, and lysate was homogenized through a 22 gauge syringe. RNA was extracted and reverse transcribed as previously described (Thorn et al. 2009, Brown et al. 2014). Quantitative real-time PCR was performed and expression of PAX7, MYF5, MYOD, MYF6, MYOG and $D E S$ was normalized to $\mathrm{S} 15$ and quantified using the $\Delta \Delta C_{\mathrm{T}}$ method. Data are presented relative to myoblast expression on day 0 .

\section{Nuclear enrichment preparations}

NE-PER Nuclear and Cytoplasmic Extraction Reagents (Thermo Fisher) were used on ground biceps femoris muscle biopsies according to manufacturer's instructions and as described previously (Brown et al. 2016). $15 \mu \mathrm{g}$ of protein was separated by gel electrophoresis and transferred to membranes as described previously. Anti-PCNA rabbit polyclonal IgG (1:500; Santa Cruz Biotechnology) was applied to the membranes. Anti-Lamin A/C mouse monoclonal IgG (1:1000; Millipore) was used to verify nuclear extraction and control for loading differences.

\section{Statistical analysis}

Unpaired $t$-tests were used for direct comparisons between CON and IUGR groups (Graph Pad Prism 5). Two-way ANOVA was used to determine the effect of IUGR (IUGR and CON) and MHC expression (Type I and Type IIa) on myofiber area, the effect of IUGR and muscle type (BF, TA and soleus) on the ratios of PAX7+ nuclei to total nuclei and Ki-67+ and PAX7+ nuclei to PAX7+ nuclei, and the effect of IUGR and insulin (insulin, FBS) on cell cycle gene expression in myoblasts (GraphPad Prism 5). Mixed models ANOVA included fixed effects for IUGR, insulin and time and accounted for repeated measures for myoblasts harvested from the same animal (SAS, version 9.1). $P \leq 0.05$ was considered statistically significant.

\section{Results}

\section{Fetal weights and physiological characteristics}

We studied the impact of IUGR on fetal body weight, physiological characteristics and skeletal muscle mass. IUGR fetal whole body weights were 35\% reduced $(P<0.0001)$, with evidence of linear growth sparing as fetal crown-rump length was only $10 \%$ reduced $(P<0.005)$ (Table 2). IUGR hindlimb muscle weights for the gastrocnemius and soleus muscles were reduced by $25 \%$ compared to CON fetal sheep when normalized to a $17 \%$ shorter lower extremity limb (LEL) length $(P<0.05)$ (Table 2). Consistent with lower muscle weights, the cross-sectional area of myofibers within the tibialis anterior and soleus muscles was reduced in IUGR compared to CON, with minor differences in the relative sizes of Type I and Type IIa myofibers (Fig. 1A and B).

As expected, fetal blood oxygen, including arterial $\mathrm{PaO}_{2}, \mathrm{O}_{2}$ saturation and blood $\mathrm{O}_{2}$ content, was all 25-35\% lower in IUGR fetuses compared to CON fetuses

Published by Bioscientifica Ltd. 
Table 2 Fetal parameters at the time of skeletal muscle collection.

\begin{tabular}{|c|c|c|c|}
\hline & Control & IUGR & $P$ value \\
\hline Measurements & $n=20$ & $n=19$ & \\
\hline Gestational age (day) & $133 \pm 0.5$ & $133 \pm 0.7$ & 0.5 \\
\hline Weight (g) & $3266 \pm 87$ & $2101 \pm 154$ & $<0.0001$ \\
\hline Crown-rump length $(\mathrm{cm})$ & $47.1 \pm 0.6$ & $42.8 \pm 1.1$ & $<0.005$ \\
\hline LEL length $(\mathrm{cm})$ & $36.6 \pm 1.2$ & $30.3 \pm 0.9$ & $<0.0005$ \\
\hline$\%$ male & 50 & 48 & \\
\hline Hindlimb muscle weights & $n=6-11$ & $n=5-8$ & \\
\hline Biceps femoris (g) & $16.67 \pm 1.79$ & $11.39 \pm 1.57$ & 0.06 \\
\hline Per LEL length $(\mathrm{g} / \mathrm{cm})$ & $0.49 \pm 0.04$ & $0.39 \pm 0.04$ & 0.1 \\
\hline Gastrocnemius (g) & $8.47 \pm 0.52$ & $5.75 \pm 0.74$ & $<0.01$ \\
\hline Per LEL length (g/cm) & $0.25 \pm 0.01$ & $0.18 \pm 0.02$ & $<0.01$ \\
\hline Tibialis anterior $(\mathrm{g})$ & $3.35 \pm 0.27$ & $2.57 \pm 0.50$ & 0.20 \\
\hline Per LEL length $(\mathrm{g} / \mathrm{cm})$ & $0.10 \pm 0.01$ & $0.07 \pm 0.01$ & 0.08 \\
\hline Soleus $(\mathrm{g})$ & $2.77 \pm 0.15$ & $2.09 \pm 0.47$ & 0.10 \\
\hline Per LEL length $(\mathrm{g} / \mathrm{cm})$ & $0.08 \pm 0.01$ & $0.06 \pm 0.01$ & $<0.01$ \\
\hline Blood gas measurements & $n=20$ & $n=19$ & \\
\hline $\mathrm{pH}$ & $7.35 \pm 0.01$ & $7.36 \pm 0.01$ & 0.5 \\
\hline $\mathrm{PaCO}_{2}(\mathrm{mmHg})$ & $48.6 \pm 2.3$ & $52.2 \pm 0.8$ & 0.1 \\
\hline $\mathrm{PaO}_{2}(\mathrm{mmHg})$ & $19.4 \pm 0.6$ & $14.4 \pm 0.8$ & $<0.0001$ \\
\hline $\mathrm{sO}_{2}(\%)$ & $44.4 \pm 1.6$ & $29.0 \pm 2.7$ & $<0.0001$ \\
\hline $\mathrm{O}_{2}$ content $(\mathrm{mmol} / \mathrm{L})$ & $3.0 \pm 0.1$ & $2.2 \pm 0.2$ & $<0.005$ \\
\hline Hct $(\%)$ & $35.2 \pm 1.3$ & $38.0 \pm 1.4$ & 0.2 \\
\hline Plasma substrates/hormones & $n=13-20$ & $n=12-19$ & \\
\hline Insulin (ng/mL) & $0.28 \pm 0.03$ & $0.17 \pm 0.02$ & $<0.005$ \\
\hline IGF1 (ng/mL) & $135.4 \pm 6.4$ & $61.5 \pm 12.1$ & $<0.0001$ \\
\hline Glucose (mg/dL) & $21.8 \pm 1.1$ & $14.4 \pm 0.9$ & $<0.0001$ \\
\hline Lactate (mmol/L) & $2.4 \pm 0.1$ & $5.0 \pm 0.9$ & $<0.01$ \\
\hline Cortisol (ng/mL) & $10.5 \pm 1.9$ & $23.6 \pm 6.8$ & 0.05 \\
\hline Norepinephrine $(\mathrm{pg} / \mathrm{mL})$ & $541 \pm 81$ & $1167 \pm 223$ & $<0.01$ \\
\hline
\end{tabular}

$(P<0.005)$ (Table 2). Fetal plasma glucose, insulin and IGF1 concentrations were 30\%, 39\% and 55\% lower, respectively, in IUGR $(P<0.005)$. Fetal plasma lactate, cortisol and norepinephrine concentrations were 2-fold higher in IUGR $(P \leq 0.05)$ (Table 2$)$.

\section{Fetal skeletal muscle gene expression, gene ontology and pathway analysis}

To determine the effect of IUGR on fetal skeletal muscle gene expression, unbiased mRNA levels were measured in late gestation CON $(n=5)$ and IUGR $(n=6)$ biceps femoris muscle using microarray technology (Affymetrix Bovine GeneChip). There were 1222 genes differentially expressed, as displayed by heat maps in Fig. 2A. Cell cycle regulation was identified as the biological process that is most different between CON and IUGR groups (enrichment score 5 out of 5) (Fig. 2B). Consistent with these findings, KEGG pathway analysis identified a pathway differentially affected by IUGR that contained 15 genes known to regulate G1 to DNA synthesis (S) phase, G2 to mitosis (M) and spindle assembly in the cell cycle. We validated the expression changes in 12 of 15 genes using real-time qPCR and found a $\sim 50 \%$ reduction (range 26-63\%) in the expression of cell cycle regulators in IUGR muscle compared to CON (Table 3) consistent with microarray expression data for those genes.

Values are means \pm S.E.M. $P$ values from unpaired $t$-tests are shown. IGF1, insulin-like growth factor-1; LEL, lower extremity limb.

A

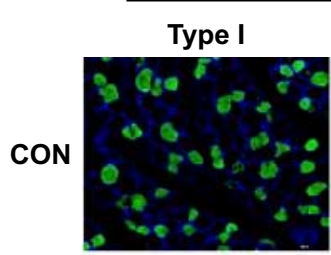
Tibialis anterior
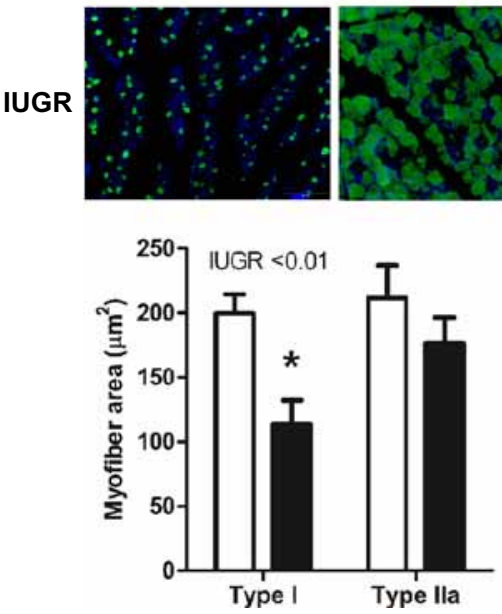

B
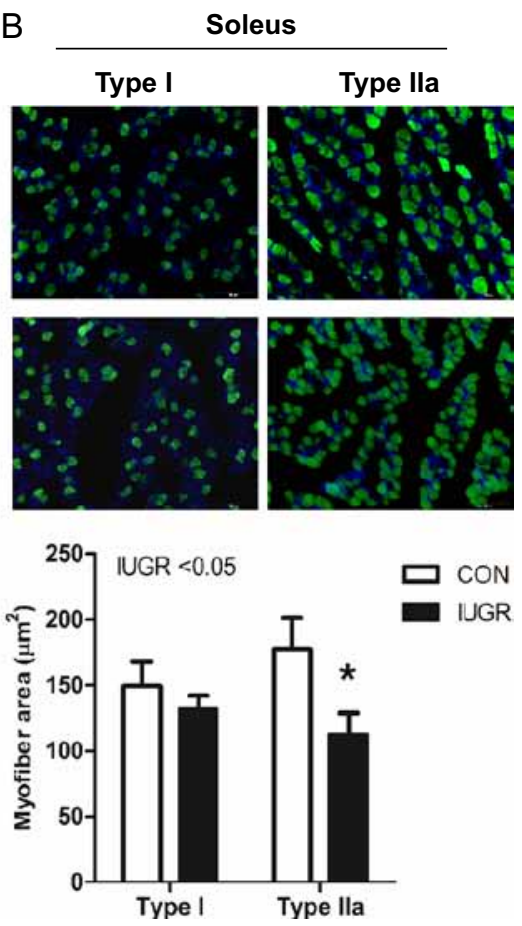

\section{Figure 1}

Myofiber cross-sectional area. Representative sections and cross-sectional area measurements of CON (white bar) and IUGR (black bar) groups for (A) tibialis anterior and (B) soleus muscle sections with an antibody against Type I and Type lla myosin heavy chain (green) and laminin (blue). Significant effects from two-way ANOVA (IUGR, myosin heavy chain type) are indicated. ${ }^{*} P<0.05$ for post-test comparisons. $N=7-9$ per group. 
A

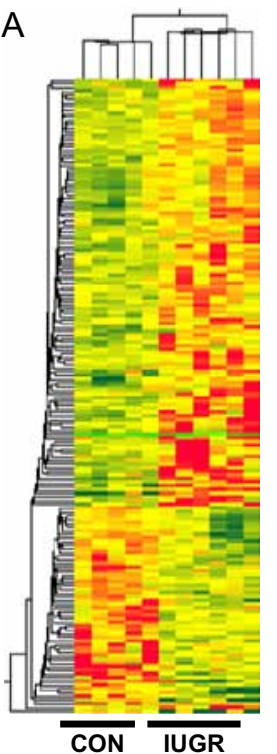

B

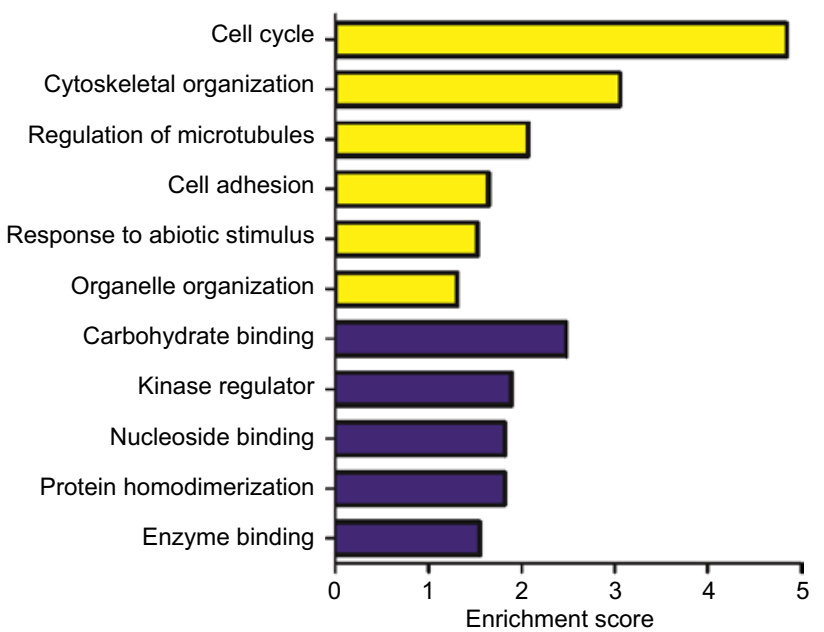

Figure 2

Heat map and gene ontology analysis. RNA from late gestation control (CON; $n=5)$ and IUGR $(n=6)$ fetal skeletal muscle was analyzed by microarray using an Affymetrix Bovine GeneChip. (A) Heat map depicting 1222 differentially expressed genes (fold change $\geq 1.5$ shown in green and $\leq 1.5$ shown in red; $P \leq 0.05$ ). (B) Ontology analysis shows gene groups within biological processes (yellow bars) and molecular functions (purple bars) that are influenced by IUGR.

\section{Fetal myoblast proliferation in vivo}

Given the microarray results which showed downregulated cell cycle genes in whole muscle tissue, we focused our attention on myoblast proliferation in vivo. The ratio of myoblasts that express PAX7 to total nuclei number and the number of PAX7+ nuclei per myofiber was measured within fetal skeletal muscle biopsies from CON $(n=8)$ and IUGR $(n=8)$ fetal sheep. The ratio of PAX7+ myoblasts per total nuclei number was increased in IUGR hindlimb muscles compared to CON (IUGR effect $P<0.05$; Fig. $3 \mathrm{~A}$ and $\mathrm{B})$, but the number of PAX7+ nuclei

Table 3 Differentially expressed genes by qPCR.

\begin{tabular}{l} 
Name \\
\hline KEGG pathway cell cycle genes \\
CCNE2 \\
CDKN2C \\
MCM6 \\
PLK1 \\
CCNB1 \\
CCNB2 \\
CDK1 \\
CDC20 \\
MAD2 \\
BUB1B \\
ESPL1 \\
CHK1 \\
MUSCle regulatory factors \\
PAX7 \\
MYF5 \\
MYF6 \\
MYOD \\
MYOG \\
DES
\end{tabular}

Gene function

Regulates $\mathrm{G} 1$ progression

Regulates G1 progression; prevents activation of CDKs Initiates DNA replication; forms replication forks and acts as a DNA unwinding enzyme

Triggers G2/M transition; supports centrosome maturation and establishes bipolar spindle

Regulates commitment to mitosis; activates CDK1 to regulate early events of mitosis

Activates CDK1

Required for the entry of cell into mitosis

Required for nuclear movement and chromosome separation

Prevents cells with incompletely assembled spindles from leaving mitosis

Involved in spindle checkpoint function

Initiates the separation of sister chromatids in mitosis

Promotes cell cycle arrest in response to DNA damage

Regulates muscle precursor cell proliferation Promotes transcription of muscle target genes Regulates myogenesis and muscle differentiation Halts proliferation for terminal cell cycle arrest in differentiated myoblasts

Required for fusion of myoblasts to myofibers Expression increases during differentiation

\begin{tabular}{|c|c|c|}
\hline \multicolumn{2}{|c|}{ Relative expression } & \multirow[b]{2}{*}{$P$ value } \\
\hline $\operatorname{CON}(n=6)$ & IUGR $(n=6)$ & \\
\hline $1.0 \pm 0.10$ & $0.54 \pm 0.10$ & $<0.005$ \\
\hline $1.0 \pm 0.05$ & $0.68 \pm 0.10$ & $<0.01$ \\
\hline $1.0 \pm 0.13$ & $0.74 \pm 0.17$ & $<0.05$ \\
\hline $1.0 \pm 0.16$ & $0.71 \pm 0.11$ & $<0.05$ \\
\hline $1.0 \pm 0.27$ & $0.37 \pm 0.09$ & $<0.05$ \\
\hline $1.0 \pm 0.22$ & $0.44 \pm 0.10$ & $<0.05$ \\
\hline $1.0 \pm 0.24$ & $0.46 \pm 0.12$ & $<0.05$ \\
\hline $1.0 \pm 0.17$ & $0.50 \pm 0.10$ & $<0.05$ \\
\hline $1.0 \pm 0.15$ & $0.56 \pm 0.09$ & $<0.01$ \\
\hline $1.0 \pm 0.23$ & $0.38 \pm 0.10$ & $<0.05$ \\
\hline $1.0 \pm 0.22$ & $0.42 \pm 0.09$ & $<0.05$ \\
\hline $1.0 \pm 0.18$ & $0.60 \pm 0.17$ & $<0.05$ \\
\hline $1.0 \pm 0.17$ & $1.20 \pm 0.25$ & 0.54 \\
\hline $1.0 \pm 0.12$ & $1.07 \pm 0.16$ & 0.73 \\
\hline $1.0 \pm 0.09$ & $0.83 \pm 0.08$ & 0.18 \\
\hline $1.0 \pm 0.25$ & $0.64 \pm 0.30$ & 0.38 \\
\hline $1.0 \pm 0.10$ & $1.01 \pm 0.15$ & 0.98 \\
\hline $1.0 \pm 0.21$ & $1.14 \pm 0.58$ & 0.61 \\
\hline
\end{tabular}

Values are means \pm S.E.M., normalized to the average of GAPDH, ACTB and RPS15 expression. $P$ values from unpaired $t$-tests are shown. http://joe.endocrinology-journals.org DOI: 10.1530/JOE-16-0123
() 2017 Society for Endocrinology Printed in Great Britain
Published by Bioscientifica Ltd 

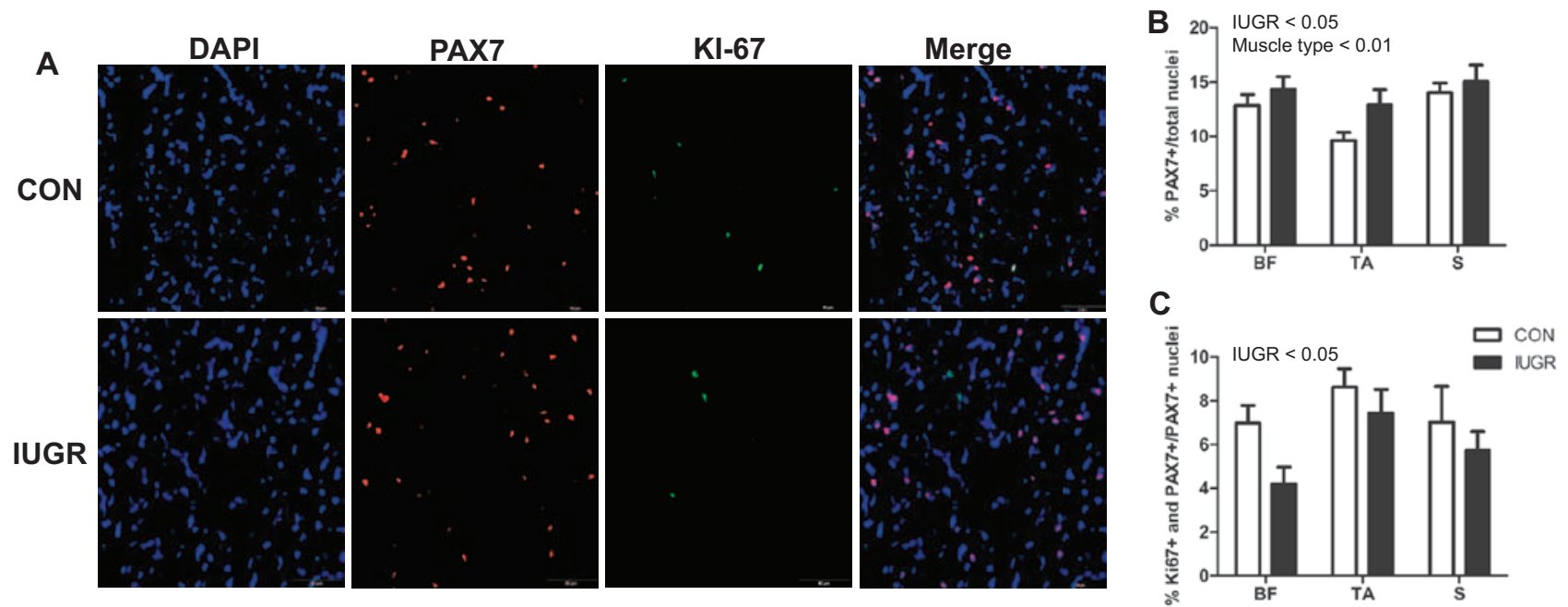

D

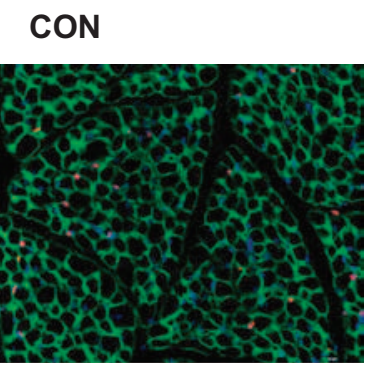

IUGR

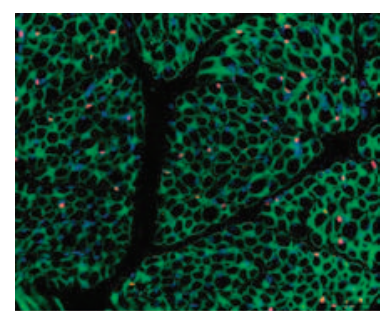

E

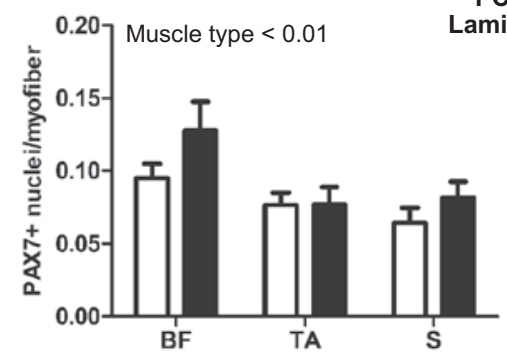

F
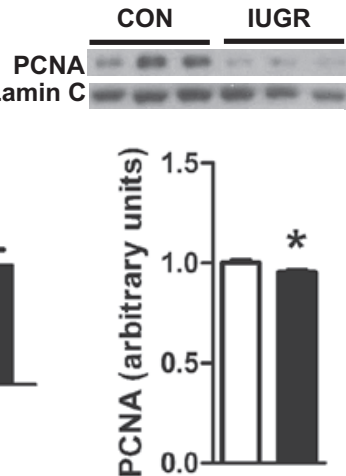

\section{Figure 3}

Myoblast proliferation in vivo. (A) Representative sections of CON and IUGR biceps femoris (BF) were stained with an antibody against PAX7 (red) and Ki-67 (green) and counter stained with a nuclear stain (DAPI). (B) The ratio of PAX7+ myoblasts to total nuclei was quantified in BF, tibialis anterior (TA) and soleus (S) muscles. (C) The ratio of PAX7+ myoblasts that were Ki-67+ was quantified in BF, TA and S muscle. (D) Representative sections of CON and IUGR BF were stained with an antibody against PAX7 (red) and laminin (green). (E) The number of PAX7+ per myofiber was quantified in BF, TA and S muscle. (F) Representative Western blots and expression of proliferating nuclear cell antigen (PCNA) and Lamin C within nuclear extracts from ground BF muscle. Significant effects from two-way ANOVA (IUGR, muscle type) are indicated. *Indicates unpaired $t$-test $(P<0.05)$. CON is shown in white bars, and IUGR is shown in black bars. $N=8$ per group.

per myofiber was similar between groups (Fig. 3D and E). The percent of PAX7+ myoblasts that also expressed Ki-67 (a marker of active cellular proliferation), however, was reduced by $23 \%$ in IUGR compared to that of CON (IUGR effect $P<0.05$; Fig. $3 \mathrm{~A}$ and $\mathrm{C}$ ). This is consistent with decreased PCNA protein expression in nuclear enriched protein fractions from the IUGR biceps femoris $(P<0.05$, Fig. 3F $)$.

\section{Capacity for fetal myoblast proliferation in vitro}

Flow cytometry demonstrated that in $\mathrm{CON}(n=7)$ and IUGR $(n=5)$ myoblast cultures, 98-99\% of cells expressed PAX7+, indicating a high level of myoblast purity in both groups (Fig. 4E). Additional flow analysis examined the relationship between PAX7 and two other myoblast markers commonly used in adult muscle, CD56, a myoblast cell surface marker, and Desmin, a cytoskeleton marker (Stewart et al. 2003). Fetal myoblasts had variable expression of Desmin (68-99\%) and CD56 (76-98\%) (Fig. 4E). Within PAX7+ cells, both control and IUGR cells had $\sim 92 \%$ expression for Desmin (Fig. 4A, B and E) and $\sim 92 \%$ co-expression with CD56 (Fig. 4C, D and E). All three myoblast markers were expressed similarly between CON and IUGR groups.

To test the intrinsic proliferative response of fetal myoblasts to insulin, myoblasts were harvested and cultured from CON $(n=6)$ and IUGR $(n=6)$ fetuses in http://joe.endocrinology-journals.org DOI: $10.1530 /$ JOE-16-0123 (c) 2017 Society for Endocrinology Printed in Great Britain 
A

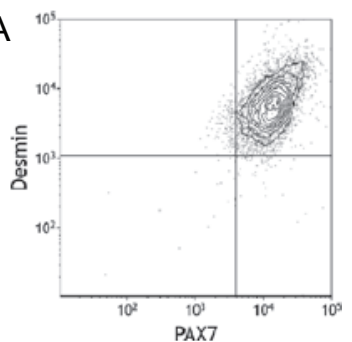

B

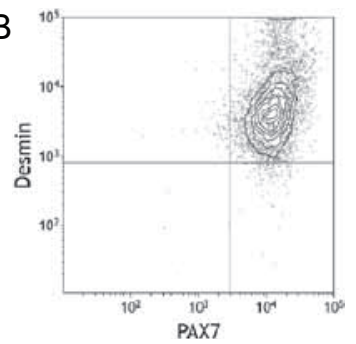

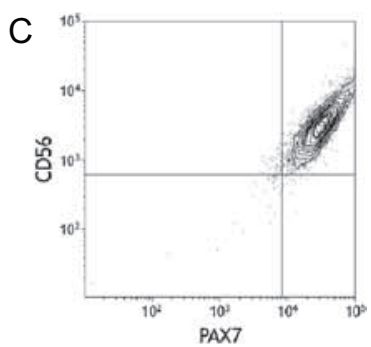

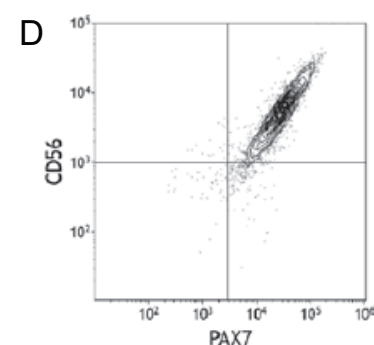

E
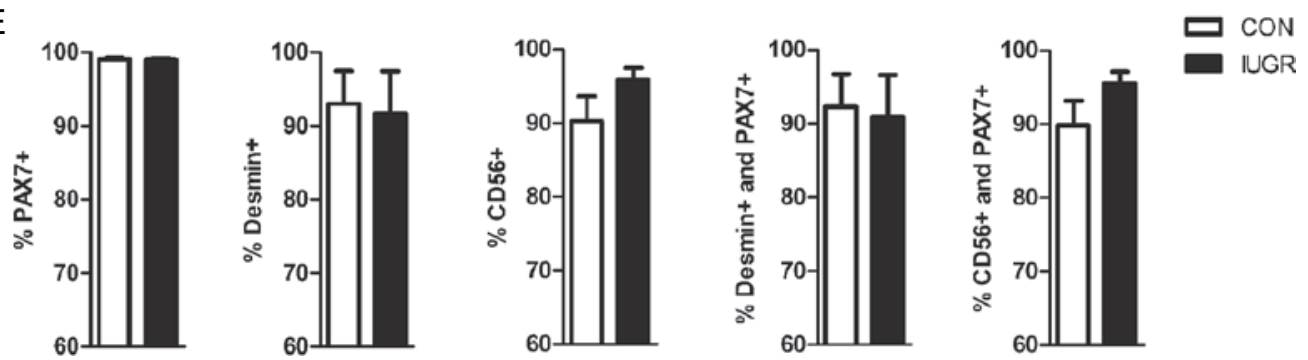

\section{Figure 4}

Fetal myoblast culture purity. Representative plots of flow cytometry of primary fetal myoblast cultures for Desmin vs PAX7 staining from (A) CON and (B) IUGR groups. Representative plots of CD56 vs PAX7 staining from (C) CON and (D) IUGR groups. (E) Quantification of events for PAX7+, Desmin+ and CD56+ only, as well as PAX7+ cells that are CD56+ and PAX7+ cells that are Desmin+. CON is shown in white bars, IUGR is shown in black bars.

$N=5-6$ per group.

SkGM with 10\% FBS and exposed to 0, 1, 10 and $100 \mathrm{nM}$ insulin. Though equal numbers of CON and IUGR myoblasts were plated, there was a $40 \%$ higher myoblast count for IUGR as compared to that for CON after $24 \mathrm{~h}$ of SkGM exposure on day $0(P<0.05)$. After 5 days, IUGR myoblasts showed an insulin dose- and time-dependent increase in cell number compared to that in CON (interaction $P<0.001$ ) (Fig. 5A).

Next, to test the effect of insulin in the absence of muscle-specific growth factors contained in SkGM, CON and IUGR myoblasts were incubated in minimally supportive media with DMEM, $100 \mathrm{nM}$ insulin and $100 \mathrm{nM}$ insulin with $1 \% \mathrm{FBS}$, and proliferation was measured by both cell count and thymidine incorporation. Though equal numbers of $\mathrm{CON}$ and IUGR myoblasts were plated, there were fewer IUGR myoblasts compared to those in CON after $24 \mathrm{~h}$ of exposure to minimally supportive media $(P<0.05)$. Myoblast number increased similarly in both CON and IUGR myoblasts only when exposed to the combination of $100 \mathrm{nM}$ insulin and 1\% FBS in DMEM (interaction $P<0.01$; Fig. 5B). Thymidine incorporation into DNA also increased in both CON and IUGR myoblasts; however, thymidine incorporation was greater in IUGR myoblasts exposed to FBS and insulin (interaction $P<0.05)$, as was their response to $100 \mathrm{nM}$ insulin alone
(IUGR myoblasts exposed to 0 vs $100 \mathrm{nM}$ insulin, $P<0.05$ by post-test comparison) (Fig. 5C).

\section{Insulin-mediated cell cycle gene expression and signaling in myoblasts}

Cell cycle regulation Given our results that showed increased proliferation in IUGR myoblasts compared to $\mathrm{CON}$, we tested whether isolated myoblasts upregulated cell cycle genes identified by KEGG pathway analysis. RNA was collected from CON and IUGR myoblasts exposed to 5 days of DMEM with and without $100 \mathrm{nM}$ insulin and 1\% FBS. Insulin with 1\% FBS increased the expression of most genes within the KEGG pathway by 25-100\% (insulin effect $P<0.05$ for PLK1, CDKN2C, CCNB1, CCNB2, CDC20, BUB1B and CHEK1), and the response was similar between CON and IUGR myoblasts (Fig. 6).

Insulin signaling To determine whether the capacity for proximal insulin signaling was intact in IUGR myoblasts, we exposed CON and IUGR myoblasts to 0, 1 and $10 \mathrm{nM}$ insulin. Phosphorylated protein-to-total protein ratios were measured at 10, 30 and $60 \mathrm{~min}$ after insulin exposure, to capture the maximal phosphorylation 

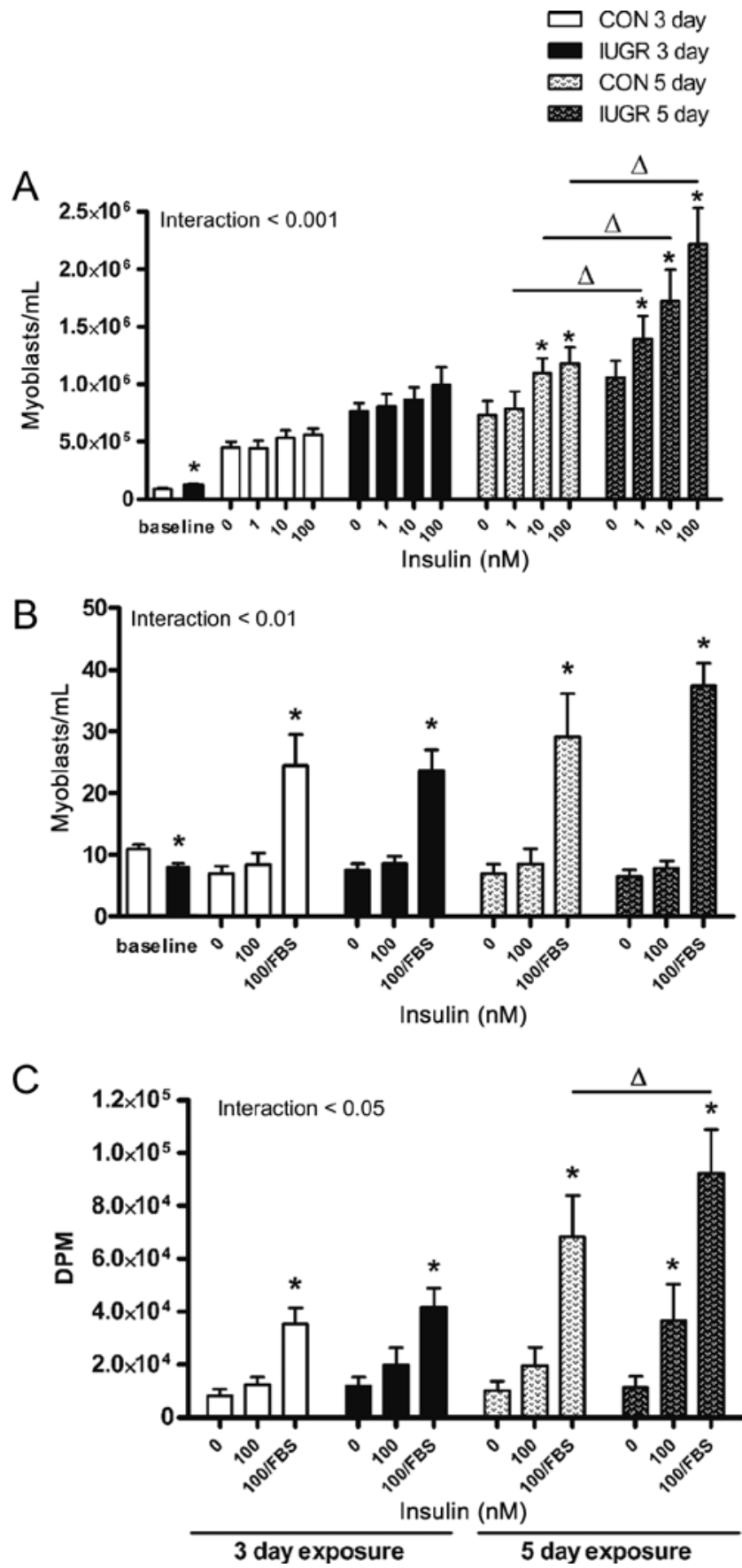

Figure 5

Fetal myoblast proliferation in vitro. Myoblasts harvested from CON and IUGR fetuses were exposed to (A) nutrient-enriched skeletal muscle growth media (SkGM) with insulin, and (B, C) minimally supportive media (DMEM) with insulin and insulin plus $1 \%$ FBS for 3 days (CON, white bars; IUGR, black bars) and 5 days (CON, white stippled bars; IUGR, black stippled bars). Myoblast counts are shown in panels $A$ and $B$, and radiolabeled thymidine incorporation is shown in panel $C$. Significant effects from mixed models ANOVA (interaction among IUGR, insulin and days of exposure) are indicated. Post-test comparisons $(P<0.05)$ compared to $* 0 \mathrm{nM}$ within time of exposure and ${ }^{\triangle} \mathrm{CON}$ vs IUGR. $N=6$ per group. of signaling proteins. There was an insulin effect, such that an increase in the phosphorylated protein-to-total protein ratio was observed for AKT, mTOR, P70S6K and p44/42 ERK1/2 with exposure to insulin (Fig. 7 and with representative blots shown in Supplementary Fig. 1, see section on supplementary data given at the end of this article). The response was similar between CON and IUGR myoblasts, with the exception of increased phosphorylation of ERK in response to insulin in CON but not IUGR myoblasts by post-test comparisons. There was a subtle but statistically significant increase in the relative total protein amounts in response to insulin for AKT, mTOR and ERK (data not shown). Of note, there was no difference in expression of any of the genes or phosphorylated protein ratios between CON and IUGR myoblasts in the basal state.

\section{mRNA expression of MRFs}

Expression of PAX7, MYF5, MYOD, MYF6, MYOG and DES did not differ in whole skeletal muscle biopsies between IUGR and CON (Table 3). Additionally, CON and IUGR myoblasts were incubated in DMEM with $2 \%$ FBS to induce differentiation over an 8-days period. As expected, PAX7 and MYF5 were expressed early in the differentiation process and MYOD, MYF6, MYOG and DES were expressed later in the differentiation process, but there was no difference between CON and IUGR groups (Fig. 8).

\section{Discussion}

We aimed to determine the impact of IUGR on fetal hindlimb muscle weight, myoblast proliferation in vivo and the intrinsic proliferative capacity of isolated fetal myoblasts in response to growth stimuli in vitro. Our investigation was driven by unbiased evaluation of gene expression by microarray that identified the downregulation of cell cycle genes in IUGR skeletal muscle biopsies. In IUGR fetuses that were hypoxemic with reduced circulating insulin and IGF1 concentrations and elevated concentrations of cortisol and norepinephrine, we found that hindlimb muscle weights and myofiber cross-sectional areas were reduced, demonstrating that skeletal muscle is disproportionately affected by IUGR. In hindlimb muscle, the pool of PAX7+ myoblasts was preserved but fewer myoblasts were actively replicating (PAX7+/Ki-67+) and nuclearenriched protein fractions expressed less PCNA. When fetal myoblasts were harvested and cultured

Published by Bioscientifica Ltd. 

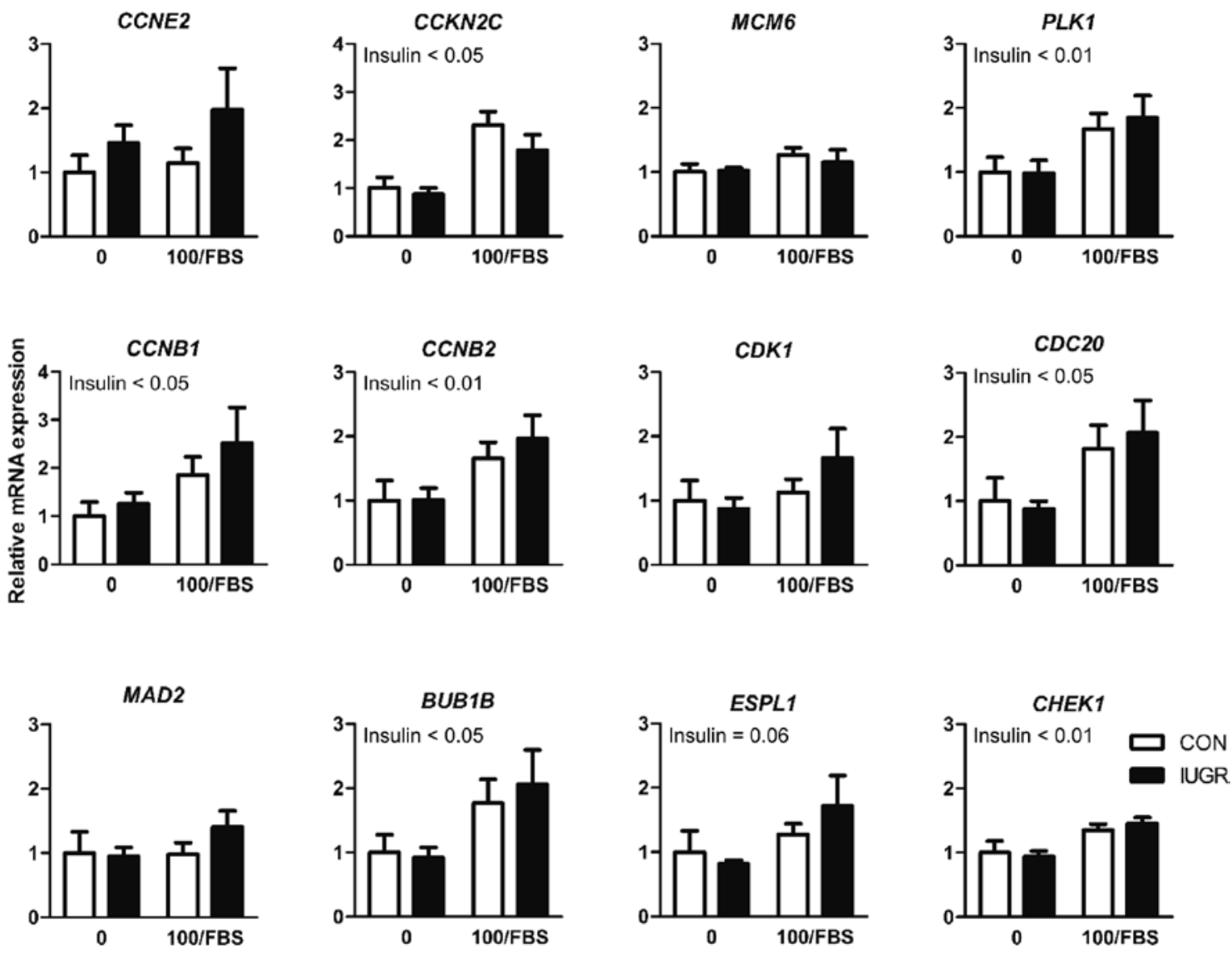

Figure 6

Myoblast cell cycle gene expression in response to acute insulin exposure in vitro. mRNA expression of cell cycle genes identified by pathway analysis in myoblasts harvested and cultured from CON (white bars) and IUGR (black bars) fetuses. Myoblasts were exposed to DMEM with no insulin or $100 \mathrm{nM}$ insulin in $1 \% \mathrm{FBS}(100 / \mathrm{FBS})$ for 5 days. All data are mean \pm s.E.M. and expressed as a fold change relative to $0 \mathrm{nM}$ insulin exposure in CON myoblasts. Significant effects from two-way ANOVA (IUGR, insulin) are indicated. $N=5-6$ per group.

in nutrient-enriched skeletal muscle growth media with insulin, however, IUGR myoblasts had increased rates of proliferation after 5 days in a dose- and timedependent manner compared to CON. Furthermore, the ability of insulin to stimulate DNA replication was higher by 5 days in IUGR myoblasts and the capacity of isolated IUGR myoblasts to upregulate key cell cycle gene expression and insulin signaling pathways in response to insulin was similar to that of CON. There were no differences in the expression of MRFs in whole muscle biopsies or in vitro. We conclude that the molecular machinery necessary for transcriptional control of proliferation by insulin and other growth stimuli remains intact in IUGR myoblasts or at least is recoverable after prolonged exposure to nutrients and anabolic hormones in vitro. In vivo factors such as reduced insulin and IGFs, hypoxia and/or elevated counter-regulatory hormones may be inhibiting muscle growth in IUGR fetuses.
The mechanisms responsible for disproportionate growth of skeletal muscle in IUGR are likely multifactorial. Human pregnancies affected by placental insufficiency are characterized by reduced umbilical blood flow, reduced net glucose and amino acid transport across the placenta to the fetus and fetal hypoxemia (Cetin et al. 1990, Economides et al. 1991, Pardi et al. 1993, Platz \& Newman 2008). Under these conditions, the fetus redistributes blood flow, oxygen and nutrients to the vital organs, such as the brain, heart and adrenal glands, at the expense of nutrient delivery to other organs, such as skeletal muscle (Tchirikov et al. 1998, Yajnik 2004). Similarly, the sheep model of IUGR used for these studies demonstrates reduced umbilical blood flow and decreased glucose and amino acid fluxes across the placenta (Brown et al. 2012), due to smaller placental size and decreased glucose and amino acid transport capacities (Thureen et al. 1992, Regnault et al. 2013). IUGR fetuses in the present studies were hypoxemic with elevated plasma norepinephrine

Published by Bioscientifica Ltd. 
A

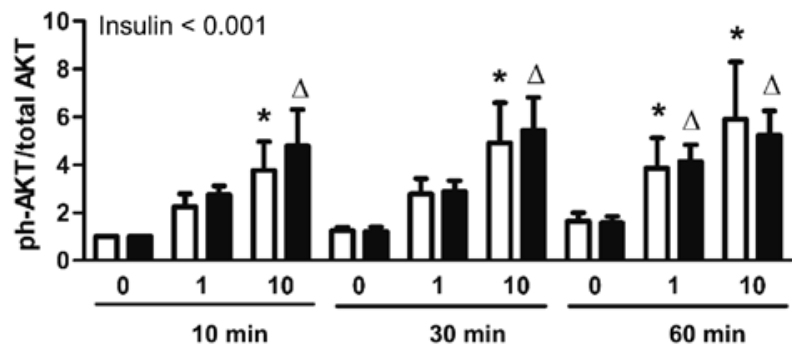

B

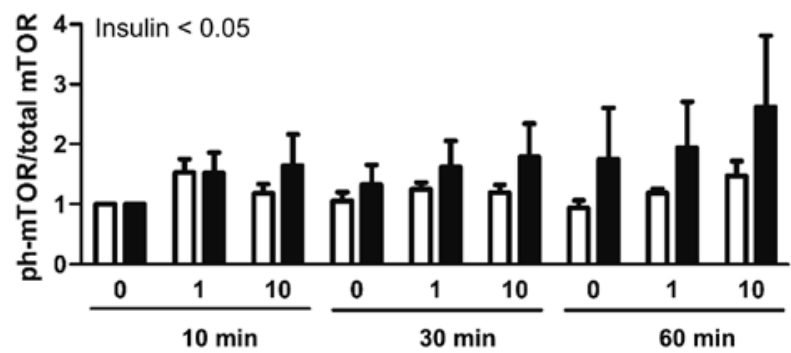

$\mathrm{C}$

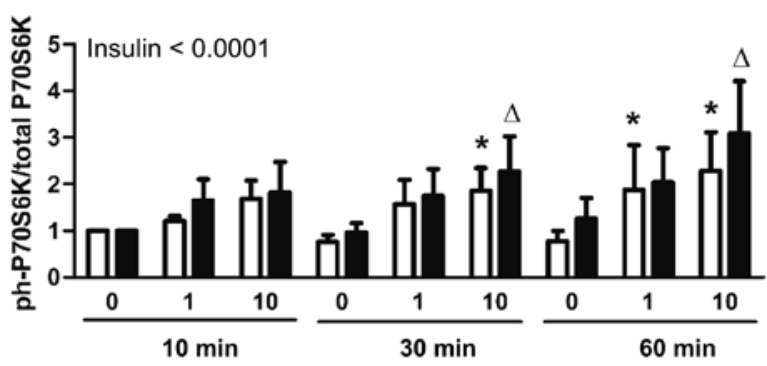

D

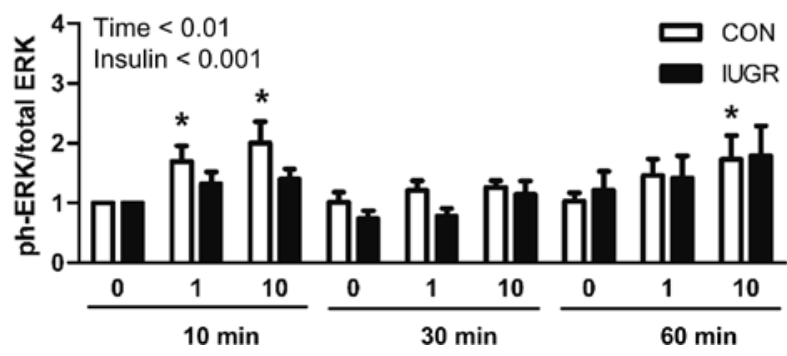

Figure 7

Insulin signaling in myoblasts. Phosphorylated to total protein ratios of (A) AKT (ph-S473), (B) mTOR (ph-S2448), (C) P70S6K (ph-Thr389), and (D) p44/42 ERK (ph-Thr202/Tyr204) in myoblasts harvested from CON (white bars) and IUGR (black bars) fetuses. Myoblasts were exposed to increasing concentrations of insulin $(0,1$, and $10 \mathrm{nM})$ in SkGM with $5 \%$ FBS for 10, 30 and $60 \mathrm{~min}$. All data are mean \pm S.E.M. and expressed as a fold change relative to $0 \mathrm{nM}$ insulin at $10 \mathrm{~min}$. Significant effects from mixed models ANOVA (IUGR, insulin and time) are indicated. Post-test comparisons $(P<0.05)$ compared to $0 \mathrm{nM}$ within time of exposure for *CON and $\triangle$ IUGR are shown. $N=5-7$ per group.

concentrations and reduced insulin and IGF1 concentrations by $40 \%$ and $55 \%$, respectively, as has been demonstrated before with this model (Brown et al. 2012).

Previous studies performed in fetal sheep have independently manipulated fetal cortisol, norepinephrine and oxygen concentrations to evaluate fetal protein accretion and skeletal muscle-specific responses. Increased cortisol concentrations produced by direct fetal infusion of cortisol during late gestation results in decreased fetal whole-body protein accretion (Milley 1995) and downregulates anabolic proteins in the mTOR signal transduction pathway within skeletal muscle (Jellyman et al. 2012). Elevated norepinephrine concentrations have been shown to limit protein accretion in the fetal lamb (Milley 1997). Fetal hypoxia as a result of chronic umbilical cord compression decreases oxygen delivery to the hindlimb and results in fetuses that are $10 \%$ smaller than sham-operated controls (Gardner et al. 2003). Deficiencies in growth factors, such as insulin and the IGF family of growth factors, also have been shown to negatively impact skeletal muscle growth and development. Pancreatectomy in fetal sheep results in growth-restricted fetuses with decreased upper and lower extremity limb length (Fowden et al. 1989). Igf1 homozygous mouse knockouts demonstrate severe muscle hypoplasia from both decreased myocyte number and myofiber cross-sectional area (Liu et al. 1993, Mavalli et al. 2010). IGF2 also plays an important role in fetal growth (Constancia et al. 2002, Randhawa 2008), with local production of IGFs being essential for normal muscle growth (Barton et al. 2012). In fact, fetal sheep myoblasts incubated in media supplemented with serum collected from the IUGR fetus show decreased proliferation rates, providing supporting evidence that extrinsic factors in the serum reduce muscle growth (Yates et al. 2014). Although the present study was not designed to determine the independent effects of each of these factors on myoblast proliferation, it is reasonable to speculate that several pathophysiological features that result from placental insufficiency reduce muscle growth in the fetus during late gestation.

Decreased expression of several cell cycle genes discovered by pathway analysis could be derived from a variety of different cell types within whole biceps femoris muscle biopsies. We directed our attention to the effects of IUGR on myoblast proliferation, as reductions in muscle mass may originate from deficiencies in myoblast replication (Widdowson 1972). We found that within whole muscle sections from biceps femoris, tibialis anterior and soleus hindlimb muscles, less PAX7+ myoblasts express Ki-67, signifying that fewer myoblasts were actively replicating. These findings are consistent with previous studies that have shown that maternal nutrient restriction during pregnancy, which also http://joe.endocrinology-journals.org DOI: $10.1530 / J O E-16-0123$
(C) 2017 Society for Endocrinology Printed in Great Britain 

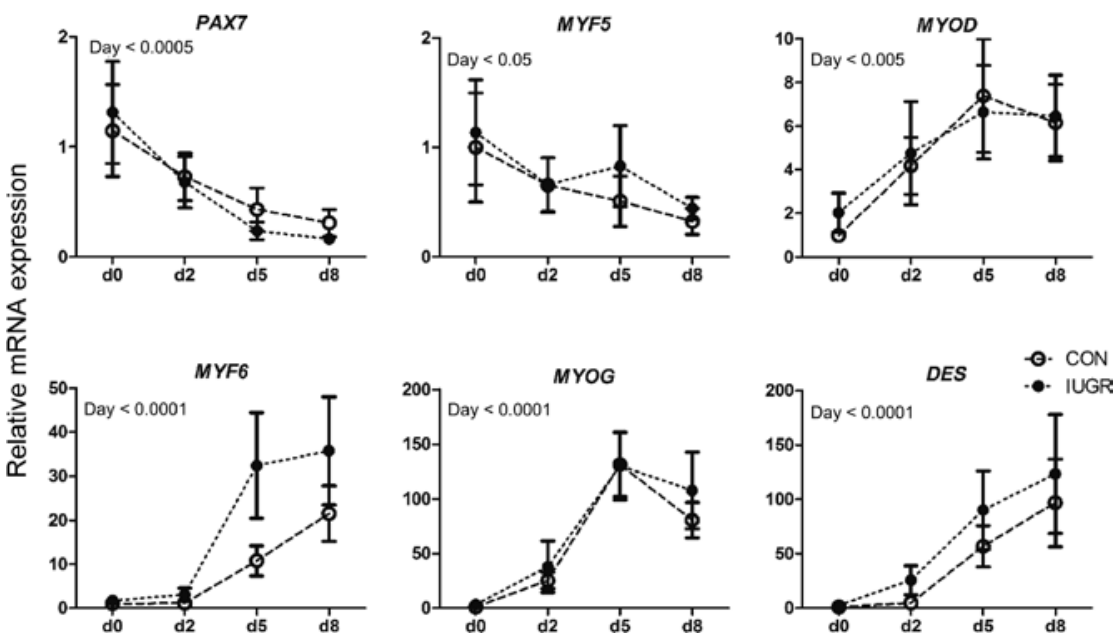

\begin{abstract}
Figure 8
Differentiating myotubes in vitro. Muscle regulatory factor expression as myoblasts from CON (white circles with dashed line) and IUGR (black circles with dotted line) fetal sheep differentiate over an 8-day period. All data are mean \pm S.E.M. and expressed as a fold change relative to day 0 in CON myoblasts. Significant effects from two-way ANOVA (IUGR, day) are indicated. $N=5-6$ per group.
\end{abstract}

results in fetal growth restriction, limits fetal myoblast cell cycle activity, reduces myonuclei per myofiber and reduces myofiber number in offspring (Wilson et al. 1988, Dwyer et al. 1995, Greenwood et al. 1999, 2000, Bayol et al. 2004, Fahey et al. 2005a, Costello et al. 2008). Similar suppressive effects on fetal myoblast proliferation and muscle growth were observed in IUGR fetal sheep (Yates et al. 2014). Interestingly, the ratio of PAX7+ to total nuclear number was increased in tibialis anterior, soleus and biceps femoris IUGR muscles compared to that in CON. However, this likely reflects the increased density of myofibers due to reduced cross-sectional area in IUGR hindlimb muscle, as the number of PAX7+ nuclei per myofiber was similar between CON and IUGR groups. These findings are consistent with maintenance of the PAX7+ pool in the fetal semitendinosus muscle after severe placental insufficiency (Yates et al. 2014), but are in contrast with a reduction in skeletal muscle satellite cells in 7-week-old pups after pregnant mice were undernourished during the last week of gestation (Woo et al. 2011). Of note, differences in the proportions of other cell types within CON and IUGR muscle tissue (including differentiated myonuclei and other vascular or immune cells not measured in this study) might influence the relative proportions of the PAX7+ pool. Additionally, gene expression patterns, the proportion of PAX7+ myoblasts and myoblast proliferation rates in vivo may vary in other muscle types in the fetus (such as the diaphragm and other upper and lower extremity muscles). The effect of IUGR on the relative proportions of other cell types within muscle, as well as the longterm significance of IUGR on the PAX7+ satellite cell population, will require further investigation.

In contrast to decreased cell cycle engagement of IUGR myoblasts in vivo, we found that proliferation of fetal
IUGR myoblasts in response to insulin when combined with other growth stimuli (SkGM and FBS) in vitro was equal to and in some conditions greater than the response of CON myoblasts. Fetal myoblast cultures were $>98 \%$ pure with PAX7+ myoblasts, thereby minimizing the possibility of fibroblast contamination affecting proliferation rates. Thymidine incorporation, which more specifically assessed DNA synthesis rates (Vega-Avila \& Pugsley 2011), was greater in IUGR myoblasts exposed to insulin for 5 days in minimally supportive media with and without $1 \%$ FBS compared to CON. In contrast, Yates and coworkers showed deficits in the intrinsic capacity for myoblast proliferation in vitro after stimulation with 3 days of growth media (Yates et al. 2014). Differences in the severity of IUGR might account for the differences in findings between studies, as IUGR fetuses in the study by Yates and coworkers were $\sim 50 \%$ smaller than those in the present study (Yates et al. 2014). Experimental conditions, including several passages and thus a longer length of time in nutrient-enriched culture conditions in our study, might also have contributed to correcting intrinsic deficiencies in myoblast proliferative capacity.

We also determined that the capacity for IUGR myoblasts to upregulate cell cycle genes identified by KEGG pathway analysis remained intact, as did the capacity for acute insulin exposure to increase AKT and mTOR activation. This is consistent with our previous findings showing similar activation of mTOR signaling in skeletal muscle after a direct, 3-h insulin infusion into IUGR and control fetal sheep (Brown et al. 2012). Our previously published work demonstrated increased insulin receptor expression in whole muscle tissue biopsies (per gram of muscle tissue) from IUGR fetuses compared to controls (Thorn et al. 2009), which could be an adaptation to maintain signaling through

Published by Bioscientifica Ltd 
insulin-responsive pathways in the context of chronic hypoinsulinemia. We also cannot exclude cross-reactivity with the IGF1 receptor and its contribution to activating growth pathways in the context of supra-physiological doses of insulin used in our studies (Nissley et al. 1985). In addition, we found no differences in the basal expression of cell cycle genes and insulin signaling proteins prior to insulin stimulation, suggesting that IUGR myoblasts are 'primed' to receive and respond to growth factors when available. Thus, we demonstrate that the IUGR myoblast has the intrinsic capacity to proliferate and activate pathways for cell growth.

There are several reasons why these observations are important. Multiple studies have shown that the human IUGR fetus and neonate have decreased muscle mass at the time of birth (Yau \& Chang 1993, Padoan et al. 2004, Larciprete et al. 2005, Beltrand et al. 2008). Deficits in muscle growth early in life are not fully recovered and thus contribute to lifelong reductions in muscle mass (Sayer et al. 2008). Furthermore, the skeletal muscle of low-birth-weight men demonstrates a phenotype of insulin resistance with decreased expression of insulin signaling proteins, which may contribute to increased risk for developing type 2 diabetes (Ozanne et al. 2005, Gluckman et al. 2008, Jensen et al. 2008). Critical developmental windows are important when considering strategies to improve muscle growth in the IUGR fetus. First, protein accretion and growth rates of skeletal muscle are maximal during the late fetal and early neonatal period (Davis \& Fiorotto 2009). Second, skeletal muscle has been shown to be more responsive to insulin in younger vs older neonatal piglets (Davis et al. 1996, Suryawan et al. 2007). Finally, deficits in fetal myoblast proliferation that reduce myofiber number could further limit the potential for restoring muscle mass outside the period of secondary myofiber formation (Ward \& Stickland 1991). Therefore, there may be only a short period of time during development when muscle growth might be recovered in IUGR fetuses, prior to the development of insulin resistance and irreversible reductions in muscle mass.

In summary, our results are the first to show the capacity of insulin along with other anabolic growth factors to stimulate IUGR myoblasts to proliferate and activate pathways for cell growth during the fetal period. However, a decreased fraction of myoblasts actively engaged in the cell cycle in the IUGR fetus in vivo indicates that extrinsic factors related to placental insufficiency and IUGR, such as reduced growth factor, hormone, oxygen and nutrient availability, may adversely influence skeletal muscle mass and myoblast proliferation. Further studies are required to determine how each of these factors regulates the process of fetal myoblast proliferation and differentiation, which should be done prior to the design of strategies to improve muscle growth in the IUGR fetus.

\section{Supplementary data}

This is linked to the online version of the paper at http://dx.doi.org/10.1530/ JOE-16-0123.

\section{Declaration of interest}

The authors declare that there is no conflict of interest that could be perceived as prejudicing the impartiality of the research reported.

\section{Funding}

L D B was supported by NIH Grants K12 HD057022 Building Interdisciplinary Careers in Women's Health Scholar Award and R01 HD079404, and The Center for Women's Health Research, University of Colorado School of Medicine. A C B was supported by NIH Grant T32 HD007186. S R W was supported by K01 DK090199. P J R was supported by NIH Grants R01 DK088139 and K08 HD060688. K B B was supported by NIH Grant T32 HL007822 and AHA Grant 13POST14410014. W W H was supported by NIH Grants T32007186-32, K12HD068372, and a Grand Challenges Exploration Grant from the Bill and Melinda Gates Foundation OPP1061082. L A L was supported by NIH Grant GM29090. C E M and B H were supported by R01 DK095926. J E F and C E M were supported by NIH Grant 2R24DK090964. Supported by the Genomics and Microarray Shared Resource of Colorado's NIH/NCI Cancer Center Support Grant P30CA046934 and the Colorado Clinical and Translational Sciences Institute NIH/NCATS Grant UL1-TR001082.

\section{References}

Barry JS, Rozance PJ \& Anthony RV 2008 An animal model of placental insufficiency-induced intrauterine growth restriction. Seminars in Perinatology 32 225-230. (doi:10.1053/j.semperi.2007.11.004)

Barton ER, Park S, James JK, Makarewich CA, Philippou A, Eletto D, Lei H, Brisson B, Ostrovsky O, Li Z, et al. 2012 Deletion of muscle GRP94 impairs both muscle and body growth by inhibiting local IGF production. FASEB Journal 26 3691-3702. (doi:10.1096/fj.11-203026)

Bayol S, Jones D, Goldspink G \& Stickland NC 2004 The influence of undernutrition during gestation on skeletal muscle cellularity and on the expression of genes that control muscle growth. British Journal of Nutrition 91 331-339. (doi:10.1079/BJN20031070)

Bell AW, Wilkening RB \& Meschia G 1987 Some aspects of placental function in chronically heat-stressed ewes. Journal of Developmental Physiology 9 17-29.

Beltrand J, Verkauskiene R, Nicolescu R, Sibony O, Gaucherand P, Chevenne D, Claris O \& Levy-Marchal C 2008 Adaptive changes in neonatal hormonal and metabolic profiles induced by fetal growth restriction. Journal of Clinical Endocrinology and Metabolism 93 4027-4032. (doi:10.1210/jc.2008-0562)

Berkes CA \& Tapscott SJ 2005 MyoD and the transcriptional control of myogenesis. Seminars in Cell and Developmental Biology 16 585-595. (doi:10.1016/j.semcdb.2005.07.006)

Braun T \& Gautel M 2011 Transcriptional mechanisms regulating skeletal muscle differentiation, growth and homeostasis. Nature Reviews Molecular Cell Biology 12 349-361. (doi:10.1038/nrm3118) 
Brown LD 2014 Endocrine regulation of fetal skeletal muscle growth: impact on future metabolic health. Journal of Endocrinology 221 R13-R29. (doi:10.1530/JOE-13-0567)

Brown LD, Rozance PJ, Thorn SR, Friedman JE \& Hay WW Jr 2012 Acute supplementation of amino acids increases net protein accretion in IUGR fetal sheep. American Journal of Physiology: Endocrinology and Metabolism 303 E352-E364. (doi:10.1152/ajpendo.00059.2012)

Brown LD, Thorn SR, O'Meara MC, Lavezzi JR \& Rozance PJ 2014 A physiological increase in insulin suppresses muscle-specific ubiquitin ligase gene activation in fetal sheep with sustained hypoglycemia. Physiological Reports 2 e12045. (doi:10.14814/phy2.12045)

Brown LD, Wesolowski SR, Kailey J, Bourque S, Wilson A, Andrews SE, Hay WW Jr \& Rozance PJ 2016 Chronic hyperinsulinemia increases myoblast proliferation in fetal sheep skeletal muscle. Endocrinology 157 2447-2460. (doi:10.1210/en.2015-1744)

Cetin I, Corbetta C, Sereni LP, Marconi AM, Bozzetti P, Pardi G \& Battaglia FC 1990 Umbilical amino acid concentrations in normal and growth-retarded fetuses sampled in utero by cordocentesis. American Journal of Obstetrics and Gynecology 162 253-261. (doi:10.1016/0002-9378(90)90860-A)

Constancia M, Hemberger M, Hughes J, Dean W, Ferguson-Smith A, Fundele R, Stewart F, Kelsey G, Fowden A, Sibley C, et al. 2002 Placental-specific IGF-II is a major modulator of placental and fetal growth. Nature 417 945-948. (doi:10.1038/nature00819)

Costello PM, Rowlerson A, Astaman NA, Anthony FE, Sayer AA, Cooper C, Hanson MA \& Green LR 2008 Peri-implantation and late gestation maternal undernutrition differentially affect fetal sheep skeletal muscle development. Journal of Physiology 586 2371-2379. (doi:10.1113/jphysiol.2008.150987)

Davis TA \& Fiorotto ML 2009 Regulation of muscle growth in neonates. Current Opinion in Clinical Nutrition and Metabolic Care 12 78-85. (doi:10.1097/MCO.0b013e32831cef9f)

Davis TA, Burrin DG, Fiorotto ML \& Nguyen HV 1996 Protein synthesis in skeletal muscle and jejunum is more responsive to feeding in 7than in 26-day-old pigs. American Journal of Physiology: Endocrinology and Metabolism 270 E802-E809.

Dennis G Jr, Sherman BT, Hosack DA, Yang J, Gao W, Lane HC \& Lempicki RA 2003 DAVID: Database for Annotation, Visualization, and Integrated Discovery. Genome Biology 4 3. (doi:10.1186/ gb-2003-4-5-p3)

Dwyer CM, Madgwick AJ, Ward SS \& Stickland NC 1995 Effect of maternal undernutrition in early gestation on the development of fetal myofibres in the guinea-pig. Reproduction, Fertility and Development 7 1285-1292. (doi:10.1071/RD9951285)

Economides DL, Nicolaides KH \& Campbell S 1991 Metabolic and endocrine findings in appropriate and small for gestational age fetuses. Journal of Perinatal Medicine 19 97-105. (doi:10.1515/jpme.1991.19.1-2.97)

Edgar R, Domrachev M \& Lash AE 2002 Gene Expression Omnibus: NCBI gene expression and hybridization array data repository. Nucleic Acids Research 30 207-210. (doi:10.1093/nar/30.1.207)

Fahey AJ, Brameld JM, Parr T \& Buttery PJ 2005a The effect of maternal undernutrition before muscle differentiation on the muscle fiber development of the newborn lamb. Journal of Animal Science $\mathbf{8 3}$ 2564-2571. (doi: $10.2527 / 2005.83112564 x$ )

Fahey AJ, Brameld JM, Parr T \& Buttery PJ 2005 $b$ Ontogeny of factors associated with proliferation and differentiation of muscle in the ovine fetus. Journal of Animal Science 83 2330-2338. (doi:10.2527/20 $05.83102330 \mathrm{x})$

Figueras F \& Gardosi J 2011 Intrauterine growth restriction: new concepts in antenatal surveillance, diagnosis, and management. American Journal of Obstetrics and Gynecology 204 288-300. (doi:10.1016/j.ajog.2010.08.055)

Finkelstein DI, Andrianakis P, Luff AR \& Walker DW 1992 Developmental changes in hindlimb muscles and diaphragm of sheep. American Journal of Physiology 263 R900-R908.

Fowden AL, Hughes P \& Comline RS 1989 The effects of insulin on the growth rate of the sheep fetus during late gestation. Quarterly Journal

http://joe.endocrinology-journals.org

DOI: $10.1530 / \mathrm{JOE}-16-0123$
๑) 2017 Society for Endocrinology Printed in Great Britain of Experimental Physiology 74 703-714. (doi:10.1113/expphysiol.1989. sp003322)

Gardner DS, Giussani DA \& Fowden AL 2003 Hindlimb glucose and lactate metabolism during umbilical cord compression and acute hypoxemia in the late-gestation ovine fetus. American Journal of Physiology: Regulatory, Integrative and Comparative Physiology 284 R954-R964. (doi:10.1152/ajpregu.00438.2002)

Gerrard DE \& Grant AL 2003 Myogenesis. In Principles of Animal Growth and Development, pp 63-75. Eds Gerrard DE \& Grant AL. Dubuque, IA, USA: Kendall/Hunt Publishing Company.

Gluckman PD, Hanson MA, Cooper C \& Thornburg KL 2008 Effect of in utero and early-life conditions on adult health and disease. New England Journal of Medicine 359 61-73. (doi:10.1056/ NEJMra0708473)

Greenwood PL, Slepetis RM, Hermanson JW \& Bell AW 1999 Intrauterine growth retardation is associated with reduced cell cycle activity, but not myofibre number, in ovine fetal muscle. Reproduction, Fertility and Development 11 281-291. (doi:10.1071/RD99054)

Greenwood PL, Hunt AS, Hermanson JW \& Bell AW 2000 Effects of birth weight and postnatal nutrition on neonatal sheep: II. Skeletal muscle growth and development. Journal of Animal Science 78 50-61. (doi: $10.2527 / 2000.78150 x$ )

Grill CJ \& Cohick WS 2000 Insulin-like growth factor binding protein-3 mediates IGF-I action in a bovine mammary epithelial cell line independent of an IGF interaction. Journal of Cellular Physiology 183 273-283. (doi:10.1002/(SICI)1097-4652(200005)183:2<273::AIDJCP14>3.0.CO;2-J)

Harper JM, Soar JB \& Buttery PJ 1987 Changes in protein metabolism of ovine primary muscle cultures on treatment with growth hormone, insulin, insulin-like growth factor I or epidermal growth factor. Journal of Endocrinology 112 87-96. (doi:10.1677/joe.0.1120087)

Jellyman JK, Martin-Gronert MS, Cripps RL, Giussani DA, Ozanne SE, Shen QW, Du M, Fowden AL \& Forhead AJ 2012 Effects of cortisol and dexamethasone on insulin signalling pathways in skeletal muscle of the ovine fetus during late gestation. PLOS ONE 7 e52363. (doi:10.1371/journal.pone.0052363)

Jensen CB, Martin-Gronert MS, Storgaard H, Madsbad S, Vaag A \& Ozanne SE 2008 Altered PI3-Kinase/Akt signalling in skeletal muscle of young men with low birth weight. PLOS ONE 3 e3738. (doi:10.1371/journal.pone.0003738)

Kanaka-Gantenbein C 2010 Fetal origins of adult diabetes. Annals of the New York Academy of Sciences 1205 99-105. (doi:10.1111/j.17496632.2010.05683.x)

Kensara OA, Wootton SA, Phillips DI, Patel M, Jackson AA \& Elia M 2005 Fetal programming of body composition: relation between birth weight and body composition measured with dual-energy X-ray absorptiometry and anthropometric methods in older Englishmen. American Journal of Clinical Nutrition 82 980-987.

Konno T \& Suzuki A 2000 Myofiber length and myofiber arrangement in the antebrachial and leg muscles of sheep. Okajimas Folia Anatomica Japonica 77 5-10. (doi:10.2535/ofaj1936.77.1_5)

Larciprete G, Valensise H, Di Pierro G, Vasapollo B, Casalino B, Arduini D, Jarvis S \& Cirese E 2005 Intrauterine growth restriction and fetal body composition. Ultrasound in Obstetrics and Gynecology 26 258-262. (doi:10.1002/uog.1980)

Leos RA, Anderson MJ, Chen X, Pugmire J, Anderson KA \& Limesand SW 2010 Chronic exposure to elevated norepinephrine suppresses insulin secretion in fetal sheep with placental insufficiency and intrauterine growth restriction. American Journal of Physiology: Endocrinology and Metabolism 298 E770-E778. (doi:10.1152/ajpendo.00494.2009)

Limesand SW, Rozance PJ, Zerbe GO, Hutton JC \& Hay WW Jr 2006 Attenuated insulin release and storage in fetal sheep pancreatic islets with intrauterine growth restriction. Endocrinology 147 1488-1497. (doi:10.1210/en.2005-0900)

Limesand SW, Rozance PJ, Smith D \& Hay WW Jr 2007 Increased insulin sensitivity and maintenance of glucose utilization rates in fetal sheep 
with placental insufficiency and intrauterine growth restriction. American Journal of Physiology: Endocrinology and Metabolism 293 E1716-E1725. (doi:10.1152/ajpendo.00459.2007)

Liu JP, Baker J, Perkins AS, Robertson EJ \& Efstratiadis A 1993 Mice carrying null mutations of the genes encoding insulin-like growth factor I (Igf-1) and type 1 IGF receptor (Igf1r). Cell 75 59-72. (doi:10.1016/s0092-8674(05)80084-4)

Marconi AM \& Paolini CL 2008 Nutrient transport across the intrauterine growth-restricted placenta. Seminars in Perinatology 32 178-181. (doi:10.1053/j.semperi.2008.02.007)

Mavalli MD, DiGirolamo DJ, Fan Y, Riddle RC, Campbell KS, van Groen T, Frank SJ, Sperling MA, Esser KA, Bamman MM, et al. 2010 Distinct growth hormone receptor signaling modes regulate skeletal muscle development and insulin sensitivity in mice. Journal of Clinical Investigation 120 4007-4020. (doi:10.1172/JCI42447)

Milley JR 1995 Effects of increased cortisol concentration on ovine fetal leucine kinetics and protein metabolism. American Journal of Physiology 268 E1114-E1122.

Milley JR 1997 Ovine fetal metabolism during norepinephrine infusion. American Journal of Physiology 273 E336-E347.

Morrison JL 2008 Sheep models of intrauterine growth restriction: fetal adaptations and consequences. Clinical and Experimental Pharmacology and Physiology 35 730-743. (doi:10.1111/j.1440-1681.2008.04975.x)

Nissley SP, Haskell JF, Sasaki N, De Vroede MA \& Rechler MM 1985 Insulin-like growth factor receptors. Journal of Cell Science Supplement 1985 (Supplement 3) 39-51. (doi:10.1242/jcs.1985.Supplement_3.5)

Ozanne SE, Jensen CB, Tingey KJ, Storgaard H, Madsbad S \& Vaag AA 2005 Low birthweight is associated with specific changes in muscle insulin-signalling protein expression. Diabetologia 48 547-552. (doi:10.1007/s00125-005-1669-7)

Padoan A, Rigano S, Ferrazzi E, Beaty BL, Battaglia FC \& Galan HL 2004 Differences in fat and lean mass proportions in normal and growthrestricted fetuses. American Journal of Obstetrics and Gynecology 191 1459-1464. (doi:10.1016/j.ajog.2004.06.045)

Pardi G, Cetin I, Marconi AM, Lanfranchi A, Bozzetti P, Ferrazzi E, Buscaglia M \& Battaglia FC 1993 Diagnostic value of blood sampling in fetuses with growth retardation. New England Journal of Medicine 328 692-696. (doi:10.1056/NEJM199303113281004)

Platz E \& Newman R 2008 Diagnosis of IUGR: traditional biometry. Seminars in Perinatology 32 140-147. (doi:10.1053/j.semperi.2008.02.002)

Randhawa RS 2008 The insulin-like growth factor system and fetal growth restrictionn. Pediatric Endocrinology Reviews 6 235-240.

Regnault TR, de Vrijer B, Galan HL, Wilkening RB, Battaglia FC \& Meschia G 2007 Development and mechanisms of fetal hypoxia in severe fetal growth restriction. Placenta 28 714-723. (doi:10.1016/j. placenta.2006.06.007)

Regnault TR, de Vrijer B, Galan HL, Wilkening RB, Battaglia FC \& Meschia G 2013 Umbilical uptakes and transplacental concentration ratios of amino acids in severe fetal growth restriction. Pediatric Research 73 602-611. (doi:10.1038/pr.2013.30)

Relaix F, Rocancourt D, Mansouri A \& Buckingham M 2005 A Pax3/Pax7dependent population of skeletal muscle progenitor cells. Nature $\mathbf{4 3 5}$ 948-953. (doi:10.1038/nature03594)

Rowe RW \& Goldspink G 1969 Muscle fibre growth in five different muscles in both sexes of mice. Journal of Anatomy $\mathbf{1 0 4} 519-530$

Sayer AA, Syddall H, Martin H, Patel H, Baylis D \& Cooper C 2008 The developmental origins of sarcopenia. Journal of Nutrition, Health and Aging 12 427-432. (doi:10.1007/BF02982703)

Stewart JD, Masi TL, Cumming AE, Molnar GM, Wentworth BM, Sampath K, McPherson JM \& Yaeger PC 2003 Characterization of proliferating human skeletal muscle-derived cells in vitro: differential modulation of myoblast markers by TGF-beta2. Journal of Cellular Physiology 196 70-78. (doi:10.1002/jcp.10322)

Suryawan A, Orellana RA, Nguyen HV, Jeyapalan AS, Fleming JR \& Davis TA 2007 Activation by insulin and amino acids of signaling components leading to translation initiation in skeletal muscle of neonatal pigs is developmentally regulated. American Journal of Physiology: Endocrinology and Metabolism 293 E1597-E1605. (doi:10.1152/ajpendo.00307.2007)

Suzuki A \& Tamate H 1988 Distribution of myofiber types in the hip and thigh musculature of sheep. Anatomical Record 221 494-502. (doi:10.1002/ar.1092210106)

Tchirikov M, Rybakowski C, Huneke B \& Schroder HJ 1998 Blood flow through the ductus venosus in singleton and multifetal pregnancies and in fetuses with intrauterine growth retardation. American Journal of Obstetrics and Gynecology 178 943-949. (doi:10.1016/S00029378(98)70528-9)

Thorn SR, Regnault TR, Brown LD, Rozance PJ, Keng J, Roper M, Wilkening RB, Hay WW Jr \& Friedman JE 2009 Intrauterine growth restriction increases fetal hepatic gluconeogenic capacity and reduces messenger ribonucleic acid translation initiation and nutrient sensing in fetal liver and skeletal muscle. Endocrinology 150 3021-3030. (doi:10.1210/en.2008-1789)

Thureen PJ, Trembler KA, Meschia G, Makowski EL \& Wilkening RB 1992 Placental glucose transport in heat-induced fetal growth retardation. American Journal of Physiology 263 R578-R585.

Vega-Avila E \& Pugsley MK 2011 An overview of colorimetric assay methods used to assess survival or proliferation of mammalian cells. Proceedings of the Western Pharmacology Society 54 10-14.

Ward SS \& Stickland NC 1991 Why are slow and fast muscles differentially affected during prenatal undernutrition? Muscle and Nerve 14 259-267. (doi:10.1002/mus.880140310)

Widdowson EM 1972 The fetus and the newborn. In Biology of Gestation, pp 1-44. Ed Assail B. New York, NY, USA: Academic Press.

Widdowson EM, Crabb DE \& Milner RD 1972 Cellular development of some human organs before birth. Archives of Disease in Childhood $\mathbf{4 7}$ 652-655. (doi:10.1136/adc.47.254.652)

Wigmore PM \& Stickland NC 1983 Muscle development in large and small pig fetuses. Journal of Anatomy 137 235-245.

Wilson SJ, Ross JJ \& Harris AJ 1988 A critical period for formation of secondary myotubes defined by prenatal undernourishment in rats. Development 102 815-821.

Woo M, Isganaitis E, Cerletti M, Fitzpatrick C, Wagers AJ, JimenezChillaron J \& Patti ME 2011 Early life nutrition modulates muscle stem cell number: implications for muscle mass and repair. Stem Cells and Development 20 1763-1769. (doi:10.1089/scd.2010.0349)

Yajnik CS 2004 Obesity epidemic in India: intrauterine origins? Proceedings of the Nutrition Society 63 387-396. (doi:10.1079/PNS2004365)

Yates DT, Clarke DS, Macko AR, Anderson MJ, Shelton LA, Nearing M, Allen RE, Rhoads RP \& Limesand SW 2014 Myoblasts from intrauterine growth-restricted sheep fetuses exhibit intrinsic deficiencies in proliferation that contribute to smaller semitendinosus myofibres. Journal of Physiology 592 3113-3125. (doi:10.1113/ jphysiol.2014.272591)

Yau KI \& Chang MH 1993 Growth and body composition of preterm, small-for-gestational-age infants at a postmenstrual age of 37-40 weeks. Early Human Development 33 117-131. (doi:10.1016/03783782(93)90207-B)

Yliharsila H, Kajantie E, Osmond C, Forsen T, Barker DJ \& Eriksson JG 2007 Birth size, adult body composition and muscle strength in later life. International Journal of Obesity 31 1392-1399. (doi:10.1038/ sj.ijo.0803612)

Received in final form 20 December 2016

Accepted 4 January 2017

Accepted Preprint published online 4 January 2017 http://joe.endocrinology-journals.org

DOI: $10.1530 / J O E-16-0123$
() 2017 Society for Endocrinology Printed in Great Britain
Published by Bioscientifica Ltd. 